\title{
Lexical Retention in Contact Grammaticalisation: Already In Southeast Asian Englishes
}

\author{
Debra Ziegeler \\ Université Sorbonne Nouvelle Paris 3 \\ dpziegeler@gmail.com
}

Sarah Lee

University of Queensland

sarah.lee@uq.edu.au

\begin{abstract}
Amongst the problems of contact grammaticalisation research in past studies has been, first, the problem of searching for diachronic evidence in relatively 'new' language situations, something which was advocated by Bruyn (2009), amongst others as essential to contact grammaticalisation research. Because of the absence of stage-bystage diachronic evidence for contact grammaticalisation, many cases of ordinary contact-induced grammaticalisation may at first appear as simply calques (polysemycopying in Heine \& Kuteva 2005). The present study reveals the presence of lexical persistence in the age-graded distribution of the perfective marker already in Singaporean and Malaysian English, and demonstrates that even ordinary contact-induced grammaticalisation may be gradual if it is mediated by constraints from the lexifier source material. The study also questions the hypothesis of Total Systemic Transfer of the Chinese perfective aspectual system in Singapore English (Bao, 2001; 2005; 2015), and suggests an extended function for the Lexifier Filter in contact.
\end{abstract}

\section{Keywords}

the lexifier - persistence in contact-induced grammaticalisation - the extension of the Lexifier Filter - age-grading in contact grammaticalisation 
It has been more than 10 years since the initial theories of contact grammaticalisation of Heine and Kuteva $(2003 ; 2005)$ were first launched, and the field of research has not been without its fair share of debate, mainly in discussion of the mechanisms by which contact grammaticalisation takes place. In Heine and Kuteva's studies, it was first argued that in the hypothesis of replica grammaticalisation speakers in contact apparently intuitively pursue the same pathways of grammaticalisation that were followed in the Model language. This was frequently misunderstood to imply that speakers were able to trace the diachronic evolution of a grammaticalising item in their L1s, and intentionally replicate it in the contact language. Such a hypothesis was often contested as being impossible (e.g. Matthews and Yip, 2009; Gast and van der Auwera, 2012; Szeto, Matthews and Yip, 2017): how, it was claimed, was it possible for speakers to "know" the diachronic evolution of the Model language and to follow it in grammaticalising categories under contact?

The process of ordinary contact-induced grammaticalisation in Heine and Kuteva's (2003; 2005) model has not escaped the judgements of its critics either; according to Bruyn (2009) many cases of ordinary contact-induced grammaticalisation may be described as "apparent grammaticalisation" or calquing (relexifying of a substrate function using lexifier material), as they were considered to proceed too fast in creoles to have gradual stage-by-stage developments. Heine and Kuteva (2005) had described similar processes as 'polysemy copying' but found that even these could often qualify as grammaticalisation processes. Bruyn (2009) has suggested that many such cases could be identified instead as simple reanalyses without grammaticalisation.

Since then, however, alternative hypotheses have been proposed, including one that suggested that speakers may not always be following the diachronic development of a grammaticalising item in the substrate or L1 model, but instead, may retrace stages of the history of the item in the lexifier, from which the lexical material was transferred in the first place (Ziegeler, 2014; 2017, Kuteva et al (to appear)). It was shown in several case studies of Singaporean and Indian English that it may in fact be possible to predict such a process, since the grammaticalisation of a lexical item should normally follow a universal process whenever the same lexical source material is used, and regardless of the circumstances under which it takes place. If that is the case, then all that remains to be investigated is whether the path of grammaticalisation is also universal across a wide range of languages and contact situations, or is unique to the lexifier model, therefore suggesting a "replication as recapitulation" hypothesis. Even in Heine and Kuteva's (2003; 2005) 'replica' grammaticalisation 
account, it is usually assumed that the Model language, which supplies the functional justification for replication in contact, is the L1 of the speakers who are creating the new language.

A further question that arises, then, is in determining when contact grammaticalisation follows the grammaticalisation processes of the substrate or L1 (replica grammaticalisation), when it follows grammaticalisation patterns of the lexifier (replication as recapitulation), and when it simply uses universal strategies of grammaticalisation, known to other contact situations (ordinary contact-induced grammaticalisation, according to Heine and Kuteva (2003; 2005)). One of the most under-researched areas of study for work in contact grammaticalisation has been the application of the five Principles of Grammaticalisation first outlined by Hopper (1991) and often used to explain monolingual grammaticalisation, but rarely applied to contact. ${ }^{1}$ The aims of the present study are to attempt to apply one of the Principles, persistence or retention (Bybee and Pagliuca, 1987), to the case of already, an aspect marker in Singapore Colloquial English and Malaysian English, and an example of ordinary contact-induced grammaticalisation according to Matthews and Yip (2009), and Szeto, Matthews and Yip (2017). Evidence will be provided of the likely adherence of lexical retention from the lexifier source material, inhibiting the grammaticalisation of the adverb with respect to the substrate functions it represents, and providing some evidence that ordinary contact-induced grammaticalisation may be more gradual than is assumed in earlier studies. The question is then raised how such lexical retention may emerge in the intuitions of native speakers, a more global problem associated with any situation of grammaticalisation.

Section 2 will look at the earlier studies on the use of already in Singapore Colloquial English and Malaysian Colloquial English (MCE), and 3 reviews the controversies surrounding the theories of contact grammaticalisation put forward by Heine and Kuteva (2003; 2005), comparing them to earlier approaches of polysemy copying and relexification. Section 3 also briefly reviews the historical development of already in English. Section 4 discusses the sociolinguistic status of English in Singapore and Malaysia, and will present the results of a spontaneous survey of the distributional range of already amongst Singaporean and Malaysian speakers, in which speakers' intuitions of lexical retention or persistence are tested against three apparently marginal uses of already as a perfective aspect marker. Section 5 discusses the survey, and the observations

1 Hopper's (1991) principles are: Layering, Divergence, Specialisation, Persistence, and Decategorialisation. They were seen by Hopper as evidence of grammaticalisation, but not necessarily applying uniquely to grammaticalisation (1991: 21). 
of generational age biases in the data. It also proposes a clearer function for the operation of the Lexifier Filter of Bao (2001; 2005) in transfer. Section 6 will summarise the study.

\section{Already in Singapore English}

The use of already as a perfective marker was first discussed by Bao (1995) as replicating the exact functions of Mandarin Chinese le in Singapore Colloquial English (Singlish). ${ }^{2}$ In earlier studies, such as Ho and Platt (1993) and KwanTerry (1989, cited in Bao, 2005), it had been recognized as at least a marker of anteriority, and other functions such as inchoativity were also observed. But Bao's study was to demonstrate that the many different functions were representative of equivalent uses in Chinese: it expressed the entire gamut of perfective functions of marking completion, inchoativity, and inception as well; i.e., other functions representative of perfective markers crosslinguistically. The adverb is clearly identified as one of the defining characteristics of contact English in Singapore, but it is not restricted to use in Singapore English. A glance at the World Atlas of Linguistic Structure (Haspelmath, Dryer et al., 2008) reveals that already is also found in MCE, and it is clearly an areal feature of the southeast Asian region, its translation equivalents appearing in many different neighbouring languages. Dahl (2006) finds 21 languages in Haspelmath, Dryer et al (eds., 2005) that have grammaticalised a perfective aspect marker from a lexical source meaning 'already' or 'finish', which led him to refer to the sources as gram-types labelled 'Iamitives'. The majority of such languages are found in the Southeast Asian region, or West Africa. Interestingly enough, personal observations show that it also appears in the L2 English of mainland Chinese students:

(1) There's no smell already (Julia, 26/2/o6, personal observation)

The use of already in (1) corresponded precisely with a use in Singaporean English, though the student who used it had never been to Singapore, nor had she had any contact with Singaporean speakers. This was an inchoative use, expressing the fact that the smell (of fish cooking) that had been there previously had now disappeared. There is evidence in such examples that the strategies that contact speakers use to grammaticalise categories in their model languages may often also be found in the grammaticalisation of L2 speakers in any contact situation. Other uses appear in New York Yiddish and South African

2 To the authors' present knowledge, there exist no detailed accounts of already in MCE. 
English, according to the Oxford English Dictionary (OED) Online (22/07/17). So the uses that Singaporeans have for already are not exceptional to the dialect, and appear to be classifiable as a universal pathway for the grammaticalisation of perfectives (see also Olssen 2013).

The Singapore English functions of already have been frequently described in past studies. Bao's (2005) study encompasses the entire aspectual system of Singapore English, in which he lists a number of functions for already. In its original conception, he argued that an entire grammatical sub-system of the substrate (usually Chinese dialects) could be transferred wholesale across to the contact language using material from the lexifier (English), as follows (Bao, 2005: 258):

\section{a. SYSTEM TRANSFER (SYSTRANS)}

Substratum transfer involves an entire grammatical subsystem.

However, the transfer was also seen to be regulated by the morphosyntax of the lexifier language:

\section{b. LEXIFIER FILTER (LEXFILTER)}

Morphosyntactic exponence of the transferred system conforms to the (surface) structural requirements of the lexical-source language.

By this means, certain unproductive distributional effects in Singapore English (Singlish) could be "filtered out" of the transfer process because they were incompatible with the syntax of English, entailing that the contact language system was not an exact replica of the substrate language system (Bao, 2015: 292).

In suggesting the Lexifier Filter as a control on effective transfer, Bao was principally referring to constraints on word order being determined by the lexical-source language (Bao, 2015: 109), as other studies he cites had previously discussed (e.g. Muhlhausler, 1986; Mufwene, 1990; Lefebvre 1998). In the case of already in Singlish or MCE, the word order of Mandarin Chinese or Cantonese, for example, which would allow already to immediately follow the verb in completive functions, is overridden by the Lexifier Filter constraints of English in which already cannot immediately follow the verb, and so the aspect marker appears sentence-finally in Singlish completive functions, e.g. as in (1) above, and (2a):

(2a)

'I (have) washed my hand' already

*II wash already my hand.' (Bao 2005: 239) 
Bao (1995) illustrated for the first time the close functional correspondence of already with the Mandarin Chinese perfective marker, le. His later, (2005) paper listed the completive use (with no reference to time) as in and (2a), but also discusses the use of the term completive to refer to the temporal sequence of clauses, in examples such as $(2 b)$.

(2b) 'After you have washed the car, I'll pay you' (Authors' gloss - DZ/SL) (Bao, 2005: 239n)

These examples are suggesting that completive means simply that the event or action must have taken place at the time of utterance, or prior to reference time. The use in clause-sequencing, then, may be considered an extension of its use in independent main clauses, as it suggests the completion of a discourse unit as well. Such functions have often been referred to in the literature as anteriors (see, e.g., Bybee, Perkins and Pagliuca, 1994), a stage of grammaticalisation preceding perfectives.

The inchoative use illustrated in (1) refers to the commencement of a new state, or a change of state - formerly there was a smell, now there is no smell. Another example of the former type of inchoative, taken from the authors' personal observation, was provided by a 4-year old child, describing the film Schindler's List:

(3) First it's colour, after that it's black and white already [...]. But at the end part it's all coloured already.

However, Bao's (2005) classifications of inchoatives also refer to the start of a new habit, a state of regular occurrences (4).

(4) Last time John was a housing agent. Now he drive taxi for a living already. ${ }^{3}$ (Bao 2005: 240)

The remaining function described by Bao (2005), the inceptive use, can also be found, often occurring ambiguously with the other two functions:

(5) Miss Lin eat cake already. (Bao 2005: Xxx)

The inceptive interpretation would entail that the subject was just about to start, or had just started eating the cake. De-contextualised, the example could

3 Last time in Singlish often means 'before'. 
also mean that she had eaten the cake (completive) or had started the habit of eating cake (inchoative), which she did not do before (Siemund, 2013: 117) also notes the absence of past tense marking co-occurring with already).

Bao's $(1995 ; 2005)$ observations were preceded by those of Platt, Weber and Ho (1984), for example, who attributed the adverb to both Singaporean and Malaysian English, suggesting it marked completive aspect, as in (6a) but they did not ignore the fact that it could also be used to mean any more, as in (6b).

(6a) My father pass away already.

(6b) I don't drink coffee already.

(Platt, Weber and Ho, 1984: 71)

However, they did not mention this as indicative of similar functions of the perfective aspect in Chinese, or in any other language with a perfective grammatical marker, the main objectives of their study being to reveal the universal features of the New English dialects. Fong (2017) claims for an Optimality Theory explanation of already in Singlish, in which the possible uses of already in Singlish are matched with the possible uses in standard English, and the compatibilities noted: important is that the diphasic nature of the perfect aspect in standard English is readily accounted for in the diphasic nature of already in Singlish which always marks a change from one state to another (2017: 91). Such grammatical constraints are significant in the process of interlingual identification (Weinreich 1953; Matras and Sakel, 2007) of polysemies by which speakers creating new replica languages of contact select forms from the lexifier to grammaticalise functions in their model languages. However, already in standard English is not an aspect marker and often only functions to reinforce perfect aspect which is already expressed in the verbal morphology. In searching for the basis of interlingual identification in the case of already, it is necessary to examine the diachrony of the adverb source as well. This will be discussed further in the sections to follow.

Other studies on the use of already in Singapore English have noted that it may appear with negation in Singlish, though not in standard (Singapore) English, e.g. (6b above), and (7).

(7) You want some more or not or don't want already?

(Bao and Hong, 2006: 198)

These uses would not appear in standard dialects elsewhere, since they illustrate an inchoative use which is not one of the functions of Standard English 
already. ${ }^{4}$ In Bao and Hong's (2006) study of the adverbs already and also in Singlish, they conclude that the Singlish use of already, which is claimed to reflect the functions of the aspect markers le (Mandarin), or liao (Hokkien), is distinguished from the standard usage by such factors as the syntactic position (it is mainly found in final position) and its co-occurrence with negation, as in $(6 b-7)$.

This is also shown in a recent study by Siemund and Li (2017) in which already (together with also) are seen to appear in the data from the Singapore National Archives Oral History Interviews (OHI). The archives data-base is taken from speakers of all professional and ethnic backgrounds, and has been collected since 1979. The earliest birthdate of the speakers in the archive collection is 1900, and Siemund and Li note that although the data is not fully representative of a diachronic corpus, the use of already and also may be traced from the time the collection was started, and as such it represents the nearest available account of the diachronic history of Singapore English. Interestingly, the data reveal some examples of already appearing twice in the same clause:

(8a) They were already actually piling their arms already.

(Siemund and Li, 2017: 20 [OHI: CORD-TMK: Reel 2])

(8b) After all this news going on, after the screening, the people were already living in fear already.

(Siemund and Li, 2017:20 [OHI: CORD-L: Reel 2]).

Siemund and Li note that the appearance of already in two positions in the clause appears to challenge Bao's (2005) hypothesis that the surface structural requirements of the lexifier will control the morphosyntax of the transferred system. However, in these two examples (8a and b), the two uses of already seem to conform to the lexifier morphosyntax though with one redundant use in each case - they do not appear to represent cases of present-day Singlish already at all. The double use of already could be interpreted as an attempt to adhere to the morphosyntactic conventions of the substrate languages, as noted by Siemund and Li (2017: 20): in Mandarin Chinese the use of the perfective marker le may be found both post-verbally and clause-finally (though usually with different functions, according to Li and Thompson (1991, and Olssen, 2013). In (8), however, the antecedent already follows the auxiliary as in standard English, and is not post-verbal as in Mandarin. In today's uses of Singlish already we rarely find both post-verbal and clause-final already co-occurring in

4 Note that in this case the lexifier functions do not inhibit the use of already in the transfer of the perfective grammatical system from the Chinese model languages. 
this way - the most frequent occurrences being clause-final, and in (8), the uses appear to indicate only the redundancy of one already. Interestingly also, Siemund and Li's (2017) study reflects the fact that it is amongst Chinese speakers of Singapore English that the use of already is the most prevalent, and this reveals a clear need to replicate a substratum function, as is discussed below.

It should be noted at this stage that the typology shown in the range of functions of already above is relevant to the present study only as far as the completive use is concerned, which, as will be shown, is the only use affected by the semantics of the lexifier. It is also interesting to note that it appears to be the only function affected by the syntactic constraints of Bao's (2005) 'lexifier filter', as seen in $(3 \mathrm{a}) .^{5}$

\section{3}

\section{Contact Grammaticalisation Studies}

Contact situations have rarely been the subject of diachronic studies, and in studying the diachrony of contact, it is difficult to make a great deal of headway, for one or more reasons: the replica language has rarely been the medium of a great deal of historical literature in many cases, and further, it has not been in existence (in some cases) for as long as a non-contact language. ${ }^{6}$ The study of grammaticalisation in contact is thus often considered somewhat tenuous. It is also noted that the length of time of grammaticalisation in a contact language is usually commensurate with the relatively small population of speakers through which the contact language diffuses, creating the illusion of accelerated development (Ansaldo, 2009: 111). Grammaticalisation in contact, therefore, formerly regarded as taking place rapidly (Heine and Reh, 1984), or abruptly in time (e.g., Bruyn, 2009) could be seen as evolving no faster than any other form of grammaticalisation, given the small speech communities through which a grammaticalisation process diffuses spatially.

On the other hand, a faster rate of grammaticalisation brought about by a smaller replicating population of speakers should enable a clearer viewpoint

5 As pointed out by an anonymous reviewer, the completive function often carries with it an additional sense of agentivity or intention on the part of the actor-subject. However, this is not believed to be a factor of persistence in the semantics of already as the typology above demonstrates inchoative functions as in examples (1) and (4), contexts which could possibly admit a reading of 'earlier than expected' though not necessarily agentivity.

6 In using the term 'non-contact' language, it is necessary to maintain some reservation, as, as Mufwene (2008: 166) and Ansaldo (2009: 97) note, a non-contact situation is marked by comparison to a contact situation, which is historically and genetically the norm in the diachronic evolution of languages. 
on the origins of many forms which are being replicated. In Heine and Kuteva $(2003 ; 2005)$ we see the foundations of a theory of contact grammaticalisation, intended for any situation of contact, creole or otherwise, and divided into two strategies:

(i) Ordinary contacted-induced grammaticalisation:

a. Speakers notice that in language $\mathbf{M}$ there is a grammatical category Mx.

b. They create an equivalent category $\mathbf{R x}$ in language $\mathbf{R}$, using material available in $\mathbf{R}$.

c. To this end, they draw on universal strategies of grammaticalisation, using construction Ry in order to develop Rx.

d. They grammaticalise $\mathbf{R y}$ to $\mathbf{R x}$.

The identification of language $\mathrm{M}$ (odel) and language $\mathrm{R}($ eplica) in Heine and Kuteva's studies is not stipulated, simply because contact can be related to many different situations. In some cases, the classifications are geographically determined, e.g. Basque has served both as a replica language (R) and a Model language $(\mathrm{M})$ with regard to Spanish (Heine and Kuteva, 2005: 4). Ordinary contact-induced grammaticalisation rests on the assumption that the material used to grammaticalise the Model function is selected on the basis of universal principles: whatever lexical concepts are frequently used cross-linguistically to grammaticalise the $\mathrm{M}$-function will be used in the contact situation, selecting the lexical material available in the language being replicated. One of the questions arising from such an account (as noted earlier) is that it is often not known whether the grammaticalisation strategy is reflective of the specific grammaticalisation patterns in the M-language or whether it just reflects a cross-linguistically universal pattern that would have been followed, whether the language was in contact with another language or not.

In order to resolve such questions, Heine and Kuteva $(2003 ; 2005)$ proposed a different strategy, less frequently found across languages, in which the stages of development seen in the R-language can be replicated in the process of transfer. They suggest a process of Replica Grammaticalisation:

(ii) Replica grammaticalisation:

a. Speakers notice that in language $\mathbf{M}$ there is a grammatical category Mx.

b. They create an equivalent category $\mathbf{R x}$ in language $\mathbf{R}$, using material available in $\mathbf{R}$. 
c. To this end, they replicate a grammaticalisation process they assume to have taken place in language $\mathbf{M}$, using an analogical formula of the kind $[\mathbf{M y}>\mathbf{M x}]=[\mathbf{R y}>\mathbf{R x}]$.

d. They grammaticalise $\mathbf{R y}$ to $\mathbf{R x}$.

The differences are thus in the evolutionary processes: in replica grammaticalisation, the entire grammaticalisation 'route' is followed by the replicating item in the contact code. The evidence of this type of strategy was in the fact that the 'routes' of grammaticalisation in contact were unique to a particular language (or rarely found) and not representative of a universal means of grammaticalisation, as was the case in ordinary contact-induced grammaticalisation. Although the original studies of Heine and Kuteva provided clear evidence for this process, for example in the case of the Irish after-perfect, a number of studies that followed questioned the possibility that speakers could assume a historical process to have taken place and were able to copy it (e.g. Matthews and Yip 2009, Gast and van der Auwera, 2012). Often the historical processes were representative of universal grammaticalisations paths anyway, and $\mathrm{Pi}$ etsch (2009) emphasized that such criticisms were misleading, as they implied that the speakers of the contact language were intentionally re-creating past stages of grammaticalisation, when in fact, it was quite often the case that earlier and later stages of grammaticalisation were found to co-exist synchronically. Matras and Sakel (2007), citing Keesing (1991), had also discussed the problems with such interpretations, suggesting that interlingual identification could involve identifying less abstract, lexical source meanings in the polysemy of certain grammatical functions words in the lexifier, which would enable the recreation of specific grammaticalisation pathways across contact. This would entail a certain degree of semantic transparency in the lexifier function words; a situation of contact "layering" would be necessary (Ziegeler 2017). The same allusion to the semantic transparency of lexifier function words has been observed by Lefebvre (2011: 24), working on Haitian Creole, who refers to the need for functional categories in the lexifier to have some semantic content in order to be "relabelled" in the contact language; for example, determiners, pronouns, tense, mood and aspect markers can be relabelled while case markers cannot. ${ }^{7}$ This suggests that more advanced grammaticalised categories which have become either too abstract or phonologically eroded for the identification of their lexical sources are less likely to be replicated.

7 Lefebvre's definition of relabelling is the use of lexifier phonological forms to represent the grammatical functions of the substrate language in contact. 
Along the same lines, Bruyn (2009) discusses the differences between ordinary contact-induced grammaticalisation and polysemy copying, or calquing, the latter held initially by Heine and Kuteva (2005) to be distinct from grammaticalisation in that it did not reflect progressive stages of development or universal patterns of grammaticalisation. Bruyn provides the case of the tense marker ben in Sranan, which is obviously derived from the English past participle been and hence it is claimed that it does not serve as an example of grammaticalisation since the original source form is not used alongside its grammaticalised counterpart; rather, it is an example of restructuring or reanalysis. However, this does not deny the possible situation of a secondary grammaticalisation (Brinton and Traugott (2005), where items that are already grammaticalised may be pressed into service for further grammatical functions, and there is no reason why such a process may not occur in contact. The only cases of polysemy copying that may not be considered grammaticalisations are those in which there is a reversal of direction (Bruyn 2009) provides the example of Sranan verbs derived from prepositions) or when there are no clear, universal parallels in other languages. In the present case of already, there is plenty of evidence of universal parallels in other languages, as mentioned above.

One of the problems with current research into contact theory is the fact that many of the disagreements are created by the tendency to compare apples with oranges: Bruyn (2009: 326) makes it clear that the kinds of contact situations demonstrated in Heine and Kuteva's (2005) study as those of long-term contact and bilingualism on a broad scale are not the same as those of rapidlydeveloping creoles. The application of creole theory to situations of postcolonial contact, as in the present study, must also consider the differences of contact situation: Singapore English, for example, has remained in constant contact with its lexifier (and some former substrate languages) throughout its entire history, as pointed out by Bao (2010: 792). It would not be surprising, then, to find the influence of the lexifier to be stronger in such cases. Theories of relexification and transfer, then, are considered to be of less significance to the Singaporean situation than to the situations of typical creoles, and the fact that Singapore English (and to a certain extent, Malaysian English) did not develop in the same way as a typical creole should be taken into consideration when comparing the present situation with other studies on contact grammaticalisation.

\subsection{Replication by Recapitulation}

Ziegeler $(2014 ; 2017)$, using the example of the comparison between the diachronic grammaticalisation and the frequency of the modal verb will in 
contact varieties of English, have demonstrated that the replication of historical stages of grammaticalisation in contact could easily be shown to have taken place in the lexifier itself. Such cases were labelled replication by recapitulation in Ziegeler (2014). For example, in the ICE-corpora, the use of will to mark habituals in Singapore and Indian English $(11.67 \%$ and $12.22 \%$ respectively) is considerably higher than in British English (3.13\%). In the Trinidad and Tobago corpus of the ICE-corpora, Deuber (2010) found that habitual will had a frequency of $14.56 \%$ in spoken usage, as against $4.72 \%$ in spoken usage in the ICE Great Britain corpus, the higher frequencies across more than one variety of 'new' English suggesting that substrate features could not have played a very significant role. Such frequencies were matched with the relatively high frequency of habituals marked with the predecessor of will in Old English texts, where $59.8 \%$ of all such uses were either habitual (described as generic) or having meanings ambiguous between habitual and volitional or habitual and future. Examples from the ICE-corpora included from Indian English (9).

(9) Everyday I will have rice then curry then uh [...] when I go to sleep I will have a glass of milk [...].

(ICE-IND: S1A-072\#214:1:A)

Such examples were compared with uses found in the Old English part of the Helsinki Corpus; e.g. (10):

(10) [...] elpendes hyd wile drincan water
elephant's hide will absorb water
'[...] elephant's hide will absorb water'
(Helsinki Corpus: Orosius 230.26.)

The latter example, having an inanimate subject, was classified as 'generic' rather than habitual, these two categories being regarded in Ziegeler (2017) as distinguished only by the nature of the subject.

In Ziegeler (2017) other case studies showed that the grammaticalisation of the indefinite article in Singlish followed the early stages of its development in Old English, as a numeral 'one', used mainly for specific or referential nouns, a crosslinguistically universal pattern of development also illustrated by Bruyn (2009) as showing abrupt grammaticalisation in Sranan. In both the Singapore case and in Sranan, the numeral form does not appear to grammaticalise to appear with non-specific nouns. In the case of Singlish, non-specific nouns remain as bare forms, as also found in Old English by Hopper (1987), before the 
numeral form had spread to non-specific contexts by Middle English. In Singapore English regular contact with the grammaticalised indefinite article available in the co-existing, standard sub-variety would obviate the need to grammaticalise one further; the functions of non-specific one would eventually be taken up by the available indefinite article, already less effortful in terms of pronunciation.

Another case of replication by recapitulation shown in Ziegeler (2017) was the appearance of the progressive aspect with stative verbs (familiar to many new varieties of English). Stative progressives were also observed in Old and Middle English; e.g. (Mustanoja 1960: 595):

$$
\begin{aligned}
& \text { (11) [...] we holden on the Crysten feyth and are bylevyng } \\
& {[\ldots] \text { we hold onto the Christian faith and are believing }} \\
& \text { in Jhesu Cryste } \\
& \text { in Jesus Christ } \\
& \text { '[...] we hold onto the Christian faith and believe in Jesus Christ.' } \\
& \text { (Mustanoja 1960: } 595 \text { [Caxton, c. 1489, Blanchardyn and Eglantine]) }
\end{aligned}
$$

In each case shown, the grammaticalisation path is not represented or replicated in its entirety, but earlier stages of development in the lexifier are simply replicated in the developing new, contact language, indicating that the grammaticalisation paths adopted by newly developing language varieties share similarities with the patterns of the lexifier in its early diachronic stages.

\subsection{Bilingual Studies of the Grammaticalisation of Already}

Amongst the critiques of the work of Heine and Kuteva (2003; 2005), Matthews and Yip (2009) and Szeto, Matthews and Yip (2017) took up the challenge to demonstrate the case of already in Singlish and Hong Kong child learner English as an ordinary contact-induced grammaticalisation, and Matthews and Yip (2009) studied give in Hong Kong child learner English as a case of replica grammaticalisation. They proposed in their study that the same strategies of grammaticalisation in contact could be applied to the stages of grammaticalisation in the bilingual child, supporting their claims with comprehensive empirical data of bilingual acquisition of Hong Kong English. Their studies carefully reveal the contrasts available: in the case of give the child progresses from lexical functions of transfer, to those of permission, and finally to passive functions, as stages of acquisition. They note, however, that in ordinary contactinduced grammaticalisation, a category in the model language is replicated (using equivalent material from the replica language) but that it does not follow the same pathway of grammaticalisation as in the replica language 
(2009: 376). This means, essentially, that the category in the model, substrate language cannot be equated to a similar category in the lexifier. In the case of already, since there is no function for the adverb to serve as an aspect marker in the pre-contact lexifier (colonial English), contact-induced grammaticalisation creates a new function in exploiting already in the replica language to serve immediately as a marker of perfective aspect, e.g. (Matthews and Yip, 2009: 378).

(12) I find already the glasses. (HKBCLC/CHILDES: Timmy, 2;07; 10) (Matthews and Yip, 2009: 378)

In (13) already marks completive functions of perfectivity. Inchoative uses are also found, e.g.,

(13) [child coming in wearing pink dress] I today wear pink. I today wear pink. [later, re-appearing in red dress] I all red already. (HKBCLC/ CHILDES: Alicia 1;10; 16)

(Matthews and Yip, 2009: 380)

The authors also point out that the uses are consistent with Cantonese uses, in which an inchoative use can be found with a stative verb, and thus Cantonese is the model language. Interesting is the fact that there is no progressive development shown in the acquisition of these functions by the children (all of the functions could have been acquired at the same time). But on the other hand, there is a 'mixing' of codes in the use of already alongside the adverb now in one of the children's uses:

(14) I open already now [holding up an opened present] (HKBCLC/ CHILDES: Timmy 2;07; 04)

(Matthews and Yip, 2009: 378)

Matthews and Yip (2009: 378) note that the introduction of now reflects the child's understanding of another adverb in English which has the closest approximation of the meaning of already in this example. This seems to suggest a reinforcement of the aspectual meanings of already, already analysed by the child. Later research undertaken by Szeto et al (2017) on Cantonese/English bilingual children's acquisition revealed that there were multiple elements in the Cantonese model language which led to the grammaticalisation in contact of already, and that the grammaticalisation of already in this way might represent only a transient stage in the children's language development. Moreover, the grammaticalisation of already, they found, was not affected by certain meanings 
associated with its use in standard English, those of 'contrary to expectation'. However, Chen (ms.) showed that there may be distributional constraints on the use of already in present-day Singapore English, possibly linked to the lexical source meanings of the adverb in the course of its historical development; these constraints inhibit the use of already with accidental events. There is evidence in the $O E D$ Online of such a developmental path; if such constraints are found, then the process of grammaticalisation of already as an aspect marker may be more gradual than at first appears. It is thus necessary to first review the historical source of already as it is used in standard English.

\subsection{On the History of Already}

The OED Online (accessed 12/08/2017) reveals that the adverb already began life as an adjectival predicate or complement, usually of the copula (as in $X$ is all ready), and thus having the meaning of 'fully prepared or ready'. The earliest uses are dated to 1200 , but no further examples are provided after the beginning of the $15^{\text {th }}$ century (in the OED). One of the earliest examples comes from Chaucer:

(15) OED Online: c1395) CHAUCE R Wife of Bath's Tale (Harl. 7334) (1885) l. 1025

$\begin{array}{lllll}\text { Al Redy }\left[\mathrm{C1405} H e n g w r t_{\text {and redy }}\right. & \text { was } & \text { his } & \text { answer } \\ \text { all } & \text { ready } & \text { was } & \text { his } & \text { Answer }\end{array}$

'His answer was all ready'

However, this function cannot be obsolete, as all ready still exists in today's English as a predicate or complement. The OED also noted that some of the later examples appear with an inherent sense of preparedness or readiness; the following could well be slightly ambiguous in meaning:

(16) OED Online: 1555 Hawes' Pastime of Pleasure (new ed.) xxix. sig. R.iiv

And founde the basket, at the grounde already and found the basket at the ground already'

'And found the basket, on the ground already/all ready'

The development of adverbial functions carried with it a slight desemanticisation of the meanings of readiness or preparedness that had accompanied its functions as a predicate or complement: the next sense provided in the OED is one in which the adverb means "before the time in question or the expected or likely time". Thus, the adverbialisation process (and univerbation) of already was already in progress by the $14^{\text {th }}$ century.

How this occurred is another matter. As noted above, adverbs are only in some cases considered to be instances of grammaticalisation; there is no 
lexemic source for the adverbialisation of already - it merely undergoes a univerbation process and a category shift. A brief search of a Corpus of Middle English Prose and Verse Online (21-22/08/17) revealed a preponderance of examples co-occurring with other words meaning 'ready', or 'in a state of preparedness', e.g. dight or boun as in (17) indicating most likely a need for lexical reinforcement of the original meanings:

... pe lord was to pe soper set:/ pe mete al redy boun the lord was to the supper sat the food all ready prepared

Vp he toke his holy hond \& $3^{\text {af }}$ pe bCenesoun up he took his holy hand and gave the blessing '... the lord had sat down at the supper: the food was all ready prepared. He raised his holy hand: and gave the blessing.

Corpus of Middle English Prose and Verse Online: 1350-1420. Cursor Mundi, Ed. Morris.

Boun is a past participle meaning 'prepared'; another use with a past participle occurs in (18):

That it be ferm with led and pich. Anon was
that it be firm with lead and pitch soon was

mad a cofre sich, Al redy broght unto his hond made a coffer such all ready brought to his hand 'That it be firm with lead and tar. Soon such a coffer was made, already brought/brought all ready to his hand'

Corpus of Middle English Prose and Verse Online: 1325-1408, John Gower's Confessio Amantis.

It is in such contexts that there is a likely ambiguity between the two functions of predicate adjective and adverb. This may have resulted from a reassignment of scope formerly extending leftwards over the antecedent NP (describing the coffer, in (19)), to extend rightwards instead over the verb participle which follows al redy (describing the manner in which it was brought). Univerbation or coalescence appears to have accompanied this reanalysis. But the adverbialisation of already in this way did not mean the disappearance of its function as a predicate adjective either, as is quite clear from Early Modern English examples, taken from the EME I file of the Helsinki Corpus: 
(19)

$\begin{array}{llllll}\text { We } & \text { found } & \text { all redy, } & \text { The lordes, } & \text { Turkis, and } \\ \text { We } & \text { found } & \text { all ready } & \text { The lords } & \text { Turks and }\end{array}$

Sarrasyns, Mamolukes, as well of Jherusalem, as of Rama.

Saracens Mamluks as well of Jerusalem as of Rama

'We found all ready, the lords, Turks, and Saracens and Mamluks, of Jerusalem, as well as of Rama.

Helsinki Corpus: 1500-1570, Torkington, Richard. Ye Oldest Diarie of Englysshe Travell Ed. W. J. Loftie.

Thus, it was evident that in the $16^{\text {th }}$ century the complement form was still in use, and in fact, still is today, as its usage in (20) would not be unusual in today's English. An example was found in the ICE-GB corpus:

(20) Pete and I were all ready to raid those camera shops.

(ICE-Great Britain:W2B-004 \#113:1)

In fact, what appears to have taken place, in grammaticalisation terms, would be likened to a 'split' (Heine and Reh, 1984) or divergence (Hopper, 1991), wherein the lexical source of a grammaticalising item continues on its usual function alongside the grammaticalising form. In the present case, the principle of a 'split' or divergence is not restricted to grammaticalisation alone, and it is clear that it may be found in other processes of category change as well.

The development of meanings of 'earlier than expected' emerging in the history of already, implied in the meanings of preparedness and expectation (readiness), are now part of the present-day polysemy of the adverb, along with the basic senses of completion. Inchoative and incipient functions are more likely to have developed in the lexifier using adverbs such as now, as shown in (15), but have never been part of the range of functions of already in the lexifier, as shown above. Thus the use of already in Singapore and Malaysian English does not replicate, stage-by-stage, any functions appearing in the history of the lexifier; it is not a replication-by-recapitulation process, nor is it a case of replica grammaticalisation as shown by Heine \& Kuteva (2005) for the after-perfect in Irish English. Since the adverb's functions are modelled on all the perfective functions of Chinese or Malay, simultaneously, the process can only be described as an ordinary contact-induced grammaticalisation, the adverb supplying the lexical source for the grammaticalisation of perfective functions, post-contact. However, as noted above, the abruptness of such processes has been questioned in previous studies (e.g. Bruyn 2009) as untypical of grammaticalisation. 
In the replication of the perfective senses of the model languages such as Malay and the Chinese dialects, it would appear that the adverb may have been selected by some speakers of Singapore English to grammaticalise all the model functions. However, Chen's (2008) study revealed some rejections of its use with accidental events, which are not exempt from perfective marking in Chinese and Malay (see section 5). Thus, it would appear that although for some speakers, there is a complete replication of all the perfective functions in the model, for others, the additional nuances of expectation and readiness (and 'earlier than expected') may be inhibiting the distributional grammaticalisation of the adverb relative to the model language grammaticalisation of perfectivity. Thus, the lexifier would be acting as a constraint on grammaticalisation, and we are not talking about a blind re-coding of a model category. We now turn to a recent empirical study of the grammatical distribution of already as a perfective marker in Singapore English and Malaysian English, in order to investigate to what extent speakers' intuitions on its present-day distribution may in fact reflect the historical meanings associated with earlier developments of the adverb.

\section{$4 \quad$ A Note on the Dialects under Review}

Singaporean and Malaysian English are often compared with one another, as they are in close geographical proximity, have some common sociocultural history including being a part of British Malaya $\left(171^{-1957)}{ }^{8}\right.$ and are seen to share similar features. However, as observed by Pennycook (1994), the divergent ideologies adopted by the two countries in terms of education, language and political priorities to manage their multilingual and multiethnic populations while at the same time remain relevant to modernisation efforts have contributed significantly to differential rates of the spread and indigenisation of English. Importantly, while English is found throughout Singapore and increasingly as a first or home language of Singaporeans $(32.6 \%$ of Chinese, $17 \%$ of Malays and $41.6 \%$ of Indians in 2010, according to Bao (2015:72)), in Malaysia, it remains a mostly urban phenomenon and is typically just one language, often not as a first language, in the repertoires of largely multilingual (at least bilingual) speakers. The divergence is potentially relevant to the issue at hand because we are looking at two locations with similar contact histories but which have since been subject to differing sets of pressure.

8 Singapore became part of British Malaya in 1819. The settlement that was to become the city of Kuala Lumpur was founded in 1857 . 
Schneider's (2003) 5-stage developmental hierarchy of 'New' Englishes provides a helpful snapshot of the global states of English in the two locations in terms of the evolution of standard as well as colloquial varieties. Singapore English is classified at Stage 4, while Malaysian English remains at Stage 3. The difference between the two stages is that while Stage 3 reflects nativisation, Stage 4 exhibits endonormative stabilization. Reasons for the disparate categorisations are primarily to do with contrasting language policy positions that have either promoted or slowed the entrenchment of English in the general population. In Singapore, the development of an endonormative standard, which Gupta (1994) has described as "varying little from any other international standard", has been encouraged by officially establishing English as the working language of government. There has also been a total conversion to English as the medium of education at all levels of schooling, with the official language of one's ethnicity a compulsory subject taught in Singapore schools, whether or not it has been acquired in the home beforehand. In contrast, the official working language of government and the public sector is Malay, and the trend of Malaysian language policy through successive governments is a commitment mostly to education in Malay, the national language and that aligned to the dominant ethnic group. Partial support for the other ethnicallyaligned languages, Mandarin and Tamil, is given in the form of availability of primary schools taught in these languages which parents of any ethnicity can select. English has not been supported extensively or consistently in the public education system since the 1970 s but is available privately, and it is not unusual for Malaysians to have spent some but not all of their schooling in Englishmedium institutions. Regardless, English enjoys a status that has emerged through its perceived value as capital for employment, further education and links to modernity. Unlike the situation in Singapore, Standard British English remains the reference standard variety.

Both locations also have colloquial varieties that are locally known as "Singlish" and "Manglish" (MCE), respectively. They possess features that vary considerably from the standard. Reflecting the English-dominant environment in Singapore, Singlish more recently has been considered to co-exist in a diglossic structure with the standard variety. It has a questionable status in Singapore, although it is sometimes accorded covert prestige amongst the locals in the search for a new cultural identity (see, e.g. Alsagoff, 2010). MCE similarly can be said to exist in diglossia, however, not just with Standard English, but in a complexity that includes other languages. (Here, we describe the conditions applicable to Greater Kuala Lumpur, which includes the capital city and surrounding areas (site of the data collection for the present study), as English does not appear consistently across the nation. English has been noticed, as a primary language of social interaction, and in various areas of education, 
the professions, and in some areas of governance (Asmah, 2012) but it is often found within multilingual strategies such as tranlanguaging and codeswitching. In fact, mixing is so prevalent that Asmah calls this way of speaking English-X, with X referencing the other language(s) speakers bring in. Ethnicity is a major factor that determines these other language(s). Intra/intergroup communications involving Malays will typically include Malay, for the Chinese, a Chinese dialect (usually Cantonese in Kuala Lumpur), Mandarin, and/ or Malay, and for Indians, Tamil or other Indian languages and/or Malay. English that is more reflective of the standard variety, i.e., fewer contact effects, is observed in domains such as the professions and various private educational sectors. The presence of English contrasts with the almost exclusive use of Malay in government and public sector communications. (Asmah, 2012). While it needs substantiation, one way we can interpret the growing difference between Singapore and Malaysia is that the former has moved away from conditions in which contact effects from intensive mixing of various languages is prevalent whereas in the latter, this is still very much the situation, with the difference being that today, Mandarin in Singapore and Malay in Malaysia are increasingly important respective adstrates.

As mentioned, both Singlish and MCE are contact varieties marked extensively by contact features, many of which are shared (Pillai, 2012) because of shared sociohistorical conditions, including common language substrates. Amongst those previously discussed specifically in the Singaporean context include the omission of pronouns (pro-drop), and the frequent use of discourse particles (usually borrowed from the languages of the historical contact ecology, as discussed comprehensively by Lim, 2007). There is also a high frequency of topicalisation (see, e.g. Bao 2001), variable use of past tense (e.g. Ho and Platt, 1993), and variable use of plural marking and indefinite articles (e.g. Author1, 2003), the use of one as a relative clause marker (Alsagoff and Ho, 1998; Bao, 2009), and as a marker of emphasis (Bao, 2009), and a universal tag question (isn't/is it), also observed in Platt, Weber and Ho (1984), and still currently in use. The features are symptomatic of the transfer of grammatical functions from the local languages, southern Chinese dialects featuring most prominently. In fact, for Singlish, it is such prolific grammatical transfer that it has motivated some researchers to admit that Singlish is "an Asian variety of English with a Sinitic-type grammar" (Ansaldo, 2009: $5^{2}$ ), and for others to suggest that the transfer is of entire grammatical systems from Chinese ( Bao 2005, 2015). MCE features are by comparison very under-studied but those abovementioned for Singlish are described as present in the Malaysian context (Azirah, 2002, 2007, Azirah \& Tan, 2012, Baskaran, 2008, Platt \& Weber, 1980, etc). We suggest therefore that the earlier stages of contact were also largely Siniticinfluenced. This has support from the sociohistories of many urban areas 
important during British Malaya period, which were characterised by majority Chinese populations. In Kuala Lumpur for instance, the proportion of Chinese residents reached $72 \%$ in 1901 (Butcher, 1979:17), and although this figure has slowly decreased through subsequent decades (to just over $50 \%$ in the 1970 (UNEsco Report 1972: 6)), Chinese-dominant Kuala Lumpur held until the last census taken in 2010 (with Malays at $45.9 \%$ and Chinese at $43.2 \%$ ). ${ }^{9}$ In addition, the uptake of English education by locals were mostly by non-Malays. To our knowledge, no substantial studies have been done on the linguistic ecologies of particular cities but it seems likely that similar to Singapore, which served as the centre of British Malaya, the various Chinese languages were significant substrates in the periods when the attested features of MCE, including localised already, emerged.

It is not surprising then that the substrate histories of Singapore and Malaysian cities (here represented by Kuala Lumpur) are similar. Substrate languages of Singapore once amounted to up to 10 southern Chinese dialects, according to Ho and Platt (1993), of which Hokkien (Fujian Southern Min) and Cantonese may be considered to hold the majority; others included Teochew (Chaozhou), Hakka (Kejia) and Hainanese, with Baba Malay spoken by the Peranakans, descendents of Chinese-Malay mixed families associated mainly with the town of Malacca in Malaysia (see, e.g. Bao, 2015: 49). Today, Malay is the national language of Singapore and is spoken by around $15 \%$ of the Singaporean population. The Chinese making up the majority of the population, at around $75 \%$ and southern Indians and others (about 6\%) do not typically use or learn Malay at all. These figures were current at the time of Ho and Platt (1993) and have changed little since then, according to Leimgruber (2009). English has the status of a neutral, lingua franca in Singapore, is a working language for all ethnicities, and is one of four official languages, the others being Malay, Tamil, and Mandarin Chinese. Mandarin has never actually been associated with the substrate, though nowadays it forms a highly active adstrate language, and bilingualism in Mandarin and English (as well as frequent code-switching) is the norm for most Chinese, for whom the former southern dialects are now mainly used for communication with the older generation.

The composition of the substrate languages of Malaysia is historically similar to that of Singapore, although impact of any one language on another will vary depending on a number of factors such as geographical area, the availability of English education, and speaker ethnicity. Various sub-varieties of Hokkien, some of which serve as lingua francas for Chinese populations in northern Malaysian cities, were and are also still present. In central Malaysian

9 Strictly speaking, the figure of $45.9 \%$ includes non-Malays who are categorised as indigenous to Southeast Asia. 
cities such as Kuala Lumpur, Cantonese is the established lingua franca amongst the Chinese and it is likely to be an important substrate at least in early periods. The influence of Malay historically in Kuala Lumpur is not likely to have been significant, in contrast to today, where urban Malay-English bilingual speakers are now highly visible, and clearly Malay features are emerging. A further complication is that spoken varieties of Malay in urban areas themselves have long been in contact with the Chinese dialects, and English. Furthermore, while Malay is the national language, its penetration into the non-Malay population as a commonly-shared linguistic resource is limited and it is still very much identified with the Malay population. In addition, the repertoires and language preferences of Greater Kuala Lumpur residents are incredibly varied, which makes generalisations applicable only to a point. Just as in Singapore, English has the status of an ethnically-neutral lingua franca but is seldom used without mixing (Lee 2015).

In a way, the sub-variety of MCE may thus be considered as representing an 'older' form of a common dialect, with features likely to have been present in Singapore English at an earlier stage of its history, where its less frequent use in the community and in fewer domains, and its continued intensive contact in a multilingual setting may mean a slower rate of internal evolution and change. The important similarities and contrasting points of the evolution of English Singapore and Malaysian contexts are summarised in Table 1.

Importantly, these differences position English in the Malaysian context as reflective of English in Singapore in an earlier period, i.e., more open to influence and at the same time, more constrained by other languages in its ecology, and make it particularly apt to study a feature such as already which was and is present in both dialects.

\subsection{Age-Grading in Variation Studies}

Age-grading as a means of measuring language change in apparent time has not been a major factor in studies on grammaticalisation in non-contact situations, let alone in contact settings, though it has long been a diagnostic in sociolinguistic studies, first exploited by Labov (1966), according to Bailey (2012). Bailey (2012: 312) describes apparent time studies as an "excellent surrogate" for real-time investigation of diachronic data, though, like many others, he advises that it must be used with caution if the objective is to determine the path of language change. For example, although Labov had undertaken apparent time studies on the understanding that the individual's vernacular stabilizes in adult life, Bailey (2012) comments on studies in which it can be seen to change according to factors relating to the individual's social environment (e.g. Sankoff and Laberge, 1978). He also refers to research in which an idiolect is shown to be still not stable in adolescence (citing Cukor-Avila, 2000), making 
TABLE 1 Summary of key characteristics of English in Singapore and Malaysia.

\begin{tabular}{|c|c|c|}
\hline Characteristic & Singapore & $\begin{array}{l}\text { Malaysia (Kuala Lumpur in } \\
\text { particular) }\end{array}$ \\
\hline $\begin{array}{l}\text { Current stage (using } \\
\text { Schneider's dynamic } \\
\text { model) }\end{array}$ & $\begin{array}{l}\text { Stage } 4 \text { - endonormative } \\
\text { stabilisation }\end{array}$ & Stage 3 - nativisation \\
\hline Support in education & Complete & $\begin{array}{l}\text { Inconsistent, unstable, } \\
\text { contested }\end{array}$ \\
\hline Official language status & $\begin{array}{l}\text { Working language of } \\
\text { government }\end{array}$ & $\begin{array}{l}\text { Partial. Used unofficially as } \\
\text { a secondary language }\end{array}$ \\
\hline Standard English & Endonormative & $\begin{array}{l}\text { Exonormative (British } \\
\text { English) }\end{array}$ \\
\hline Use for social interaction & $\begin{array}{l}\text { Extensive for all groups } \\
\text { and domains }\end{array}$ & $\begin{array}{l}\text { Extensive for some urban } \\
\text { sub-communities, mostly } \\
\text { non-Malays, lingua franca } \\
\text { for educated across } \\
\text { ethnicities }\end{array}$ \\
\hline Diglossia & $\begin{array}{l}\text { Standard and colloquial } \\
\text { varieties }\end{array}$ & $\begin{array}{l}\text { Standard, colloquial } \\
\text { varieties, other languages } \\
\text { (Malay, Mandarin, } \\
\text { Cantonese) }\end{array}$ \\
\hline Significant substrate & Hokkien, Cantonese, other & Cantonese, Hokkien, other \\
\hline languages & $\begin{array}{l}\text { Chinese dialects, Baba } \\
\text { Malay, Malay, Mandarin } \\
\text { (more reent) }\end{array}$ & $\begin{array}{l}\text { Chinese dialects, colloquial } \\
\text { Malay (possibly more } \\
\text { recent) }\end{array}$ \\
\hline Significant adstrates & Mandarin & $\begin{array}{l}\text { Cantonese, Malay, Mandarin } \\
\text { (growing) }\end{array}$ \\
\hline $\begin{array}{l}\text { No. of first language } \\
\text { speakers }\end{array}$ & $\begin{array}{l}32.6 \% \text { of Chinese, } 17 \% \\
\text { of Malays and } 41.6 \% \text { of } \\
\text { Indians spoke English as } \\
\text { their home language in } \\
2010\end{array}$ & $\begin{array}{l}5 \%(2005) \text { but is most likely } \\
\text { higher in urban areas }\end{array}$ \\
\hline
\end{tabular}

comparisons with such age-groups somewhat risky. Furthermore, he notes that although resurveying the same participants decades later may be necessary to prove the viability of apparent-time studies, real-time research of this kind is quite difficult to undertake in terms of achieving adequate precision in repetitions of the same methodology. 
Wagner (2012: 377) also mentions the difficulties of assuming too much from the results of apparent-time studies, and cites Wagner and Sankoff (2011) who found that some speakers tend to revert from innovative uses to more conservative uses as they grow older - in their study, it was the use of the periphrastic future tense form versus the more conservative inflected future form in Montreal French. This indicates that it may be often social pressures that influence the selection of alternative forms in language change - innovative forms are associated with younger speakers. However, it is not necessarily an indication of the reversal of the direction of change across a community, as a conservative use will disappear with the life-span of its (older) speakers, leaving a period of longer duration for more innovative uses to remain in the speech community.

Much of the earlier research using apparent-time methods was centred around variationist work examining phonological features across English dialects. Less research has been undertaken with a view to combining grammaticalisation research with apparent-time studies, an obvious starting point from which to investigate rapid grammaticalisation changes over time. One recent grammaticalisation study to consider the apparent-time factor has been Tagliamonte, Durham and Smith (2014), whose study of be going to in British and Canadian English showed a more conservative use of the periphrastic future with speakers aged 66 or over than with younger speakers. They cite Brinton and Traugott (2005) who emphasise the importance of frequency as evidence for the grammaticalisation of a form diachronically: more frequent token counts usually entail a higher level of grammaticalisation. Frequency patterns can be readily measured across diachronic corpus texts, but it is less often the case that statistical frequency across generations of speakers can be seen to provide insight into the rate of grammaticalisation of a feature. Hopper and Traugott (2003: 239) also allude to the importance of increased diachronic frequency levels related to generational differences (which may thus reveal increasing levels of grammaticalisation). In Tagliamonte et al's (2014) study, age and generational differences were cross-factorised into the total results together with effects of linguistic environment and geographical differences. In doing so, it can be seen that the increased frequency of the item was due to an increase in the range of linguistic environments in which it was used as it became grammaticalised amongst younger speakers.

Other studies which have referred to generational differences in grammaticalisation have included Schwenter (1994), who found, in his study of the hodiernal perfect in Alicante Spanish, that speakers aged 40 and above had a more restricted use of it than speakers aged 18-25 to refer to events in the past (without current relevance) which happened on the day of speaking. The use of the preterite rather than the present perfect amongst the older speakers 
was $27 \%$ as against only $6 \%$ amongst the younger speakers, illustrating that the generalization of the present perfect to a wider distributional range of environments was taking place faster in the younger generation of speakers. Romaine and Lange (1991) also refer to age-grading effects in their review of the grammaticalisation of the quotative marker like in English, using a range of studies for their evidence.

\subsection{Empirical Investigations}

The following surveys take into consideration the factor of age-grading in the grammaticalisation of already in Singapore and Malaysian English, using intuitive judgements to test for distributional preferences as evidence of the presence of lexical persistence in the use of already. The presence of lexical persistence is hypothesized to reflect levels of distributional grammaticalisation across apparent time.

\subsubsection{The Singapore Survey}

A brief questionnaire (which had already been tested as a pilot study using 19 informants) was posted online as a Google application, ${ }^{10}$ with the following sample sentences for evaluation:

\section{i. Aiyah! I hurt my hand already! \\ ii. Aiyoh! I lost my wallet already! \\ iii. Wah lao! My computer crash already! ${ }^{11}$}

All three sentences referred to accidental events, the first one having formerly been used in Chen's exercise. The participants in the Singapore study were completely anonymous, the only information requested of them being whether they were brought up from childhood in Singapore or Malaysia, and their age. The single question to be answered was whether the sample sentences were "good" Singlish or not, and the response categories were: Good, Possible but not Good, and Bad. The intermediate category of evaluation, Possible but

10 The link to the Singapore survey may be found on: https://docs.google.com/forms/d/1 Hjf rNxRPWhaWxT9 $\mathrm{C}_{3}$ XBRpr4ePydDrcPYS8d6LIi5_To/edit?ts=599eefe7.

11 The sentences were accompanied by appropriate discourse markers (aiyah, aiyoh and wah lao) in order to emphasize the accidental nature of the event described, as suggested by one participant in the pilot survey. The absence of past tense marking (particularly for regular pasts, as in sentence 3) is frequent in Singlish when the verb co-occurs with already as a completive marker, as noted above. 
not good was taken to allow for judgements that might include rejection but with the additional speculation that the example sentence could occur. The objective in simplifying the survey format in this way was to avoid the appearance of an academic survey, which would most likely elicit an over-careful or less spontaneous response, or maybe none at all (in cases in which the participant did not wish to be seen condoning non-standard usage). Another reason was the time factor, since many speakers could be turned away from a survey that was too wordy, and the speed of a rapid, simple ('fun') survey was thus likely to be more appealing. The survey hyperlink was first sent out to various Singaporean contacts via smartphone applications such as What's Ap and Facebook; the contacts then forwarded it on to increasingly wider social networks until a total of 45 responses was eventually received (one had to be rejected), after which the incoming responses started to slow down and the site was then closed. The first respondents were asked not to discuss the answers amongst themselves, but as the networks rapidly broadened, this became a factor that was naturally difficult to control. However, there did not appear to be any immediate evidence of priming in the answers, which were collected in the order in which they came in. The majority of the data was obtained over a period of less than one week.

The speed and brevity of the survey precluded the advantages of assembling large amounts of sociolinguistic biodata such as details about the participants' education or professional status. However, questions requesting such information might have provided unnecessary distractions from the main objectives of the task and made the respondents more reflective of the social status of Singlish, since (as noted earlier) Singlish has an ambiguous identity in Singapore. The minimal background information regarding place of up-bringing and age were considered less likely to create such problems. 21 of the respondents were aged under $5^{0}$ and 23 were aged $50^{+}$. The 50 -year cut-off point was seen as providing a diachronic perspective on the data, and along with this, enabling predictions to be made according to apparent-time gradings (cf., e.g. Labov, 1966; Bailey, 2004; Wagner, 2012). Singapore's political independence was established in 1965, after which English-medium education became the norm everywhere, and thus age-grading was considered a significant factor. The following tables illustrate the results obtained.

Given that the category Possible, but not good, rules out accepting the usage, even though it might have been considered a possible usage, the data above thus reveal the following relative frequencies in terms of rejection:

Under 5os group (21): o Bad, 19 Possible but not good responses, across 126 possible rejections. $19 / 126=15.07 \%$ rejections in the entire group. 
TABLE 2 Evaluations of 3 sentences using already as an aspect marker in Singlish: participants aged under 50:

$\mathrm{N}=21$

\begin{tabular}{llccrc}
\hline & Good & \% & Possible but not good & \% & Bad \\
\hline Q1 & 17 & 26.9 & 4 & 6.3 & 0 \\
$\mathrm{Q}_{2}$ & 11 & 17.4 & 10 & 15.8 & 0 \\
$\mathrm{Q}_{3}$ & 16 & 25.3 & 5 & 7.9 & 0 \\
Total $=63$ & 44 & 69.8 & 19 & 30.1 & 0 \\
\hline
\end{tabular}

TABLE 3 Evaluations of 3 sentences using already as an aspect marker in Singlish: participants aged $50+$

$\mathrm{N}=23$

\begin{tabular}{|c|c|c|c|c|c|c|}
\hline & Good & $\%$ & Possible but not good & $\%$ & Bad & $\%$ \\
\hline $\mathrm{Q}_{1}$ & 8 & 11.5 & 12 & $17 \cdot 3$ & 3 & $4 \cdot 3$ \\
\hline $\mathrm{Q}_{2}$ & 8 & 11.5 & 11 & $15 \cdot 9$ & 4 & $5 \cdot 7$ \\
\hline $\mathrm{Q}_{3}$ & 11 & $15 \cdot 9$ & 9 & 13 & 3 & $4 \cdot 3$ \\
\hline Total $=69$ & 27 & 39.1 & 32 & 46.3 & 10 & 14.4 \\
\hline
\end{tabular}

TABLE 4 Summary of Singlish results (\%): both groups.

\begin{tabular}{|c|c|c|}
\hline & Good Singlish & $\begin{array}{l}\text { Either possible but not good or } \\
\text { bad Singlish }\end{array}$ \\
\hline Under 50 group & 69.8 & $3^{0.1}$ \\
\hline $5^{0}+$ group & 39.1 & 60.7 \\
\hline
\end{tabular}

For the 50+ group (23): $10 \mathrm{Bad}, 3^{2}$ Possible but not good responses $=42$ rejections in total, across 138 possible rejections. $42 / 138=30.4 \%$ of the entire group $=101.7 \%$ more than the Under 50 group.

Bearing in mind that the rejections in the Under 5os group were derived solely from the slightly weaker evaluation, Possible but not good, the proportions are seen in Figures 1 and 2 to be almost the converse of each other. 


\section{Under $5^{\circ}$ Group (Singlish)}

Acceptances $\square$ Rejections

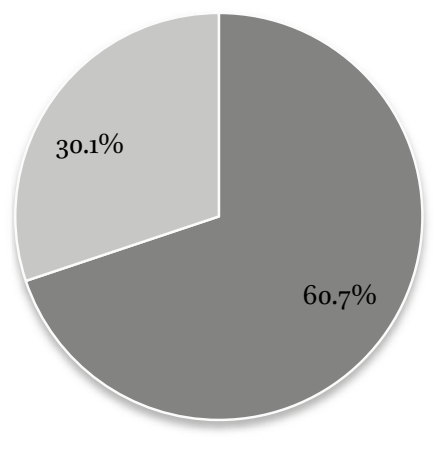

FIGURE 1

Results summary for the respondents in the Singapore group aged under $5^{0 .}$

\section{5o+ Group (Singlish)}

\section{Acceptances Rejections}

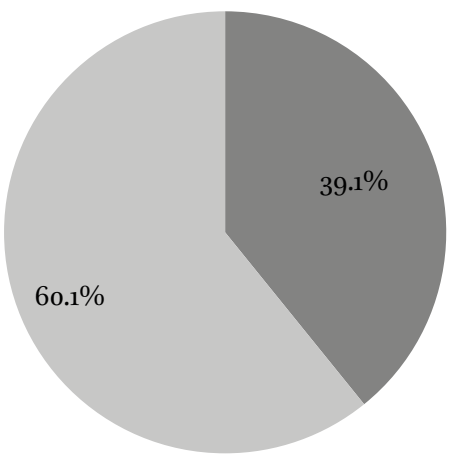

FIGURE 2

Results summary for the respondents in the Singapore group $50+$.

\subsection{The Malaysian English Survey}

The same survey was distributed as a Google online survey, as with the Singapore group, via a social network of internet applications, ${ }^{12}$ to speakers of Malaysian English in Kuala Lumpur. One of the sentences (iii) was changed slightly to allow for a more typical, local use of the discourse particle: instead of Wah lao! My computer crash already! it was presented as: Aiyeh! My computer crash already!. For the Malaysian English survey, the final numbers of

\footnotetext{
12 https://docs.google.com/forms/d/_BxYeR4LFOiJFz93ezyjzkkEBwdxas2oWEicUuxws2oo/ edit?ts $=59 \mathrm{c} 6 \mathrm{dg}$ bb.
} 
TABLE 5 Evaluations of 3 sentences using already as an aspect marker in MCE: participants aged under 50 :

$\mathrm{N}=78$

\begin{tabular}{|c|c|c|c|c|c|c|}
\hline & Good & $\%$ & Possible but not good & $\%$ & Bad & $\%$ \\
\hline Q1 & 23 & 9.8 & 36 & $15 \cdot 4$ & 19 & 8.1 \\
\hline $\mathrm{Q}_{2}$ & 25 & 10.7 & 34 & 14.5 & 19 & 8.1 \\
\hline Q3 & 15 & 6.4 & 36 & 15.4 & 27 & 11.5 \\
\hline Total $=234$ & 63 & 26.9 & 106 & $45 \cdot 3$ & 65 & 27.8 \\
\hline
\end{tabular}

TABLE 6 Evaluations of 3 sentences using already as an aspect marker in MCE: participants aged $50+$ :

$\mathrm{N}=23$

\begin{tabular}{lcrrrrr}
\hline & Good & \% & Possible but not good & Bad & $\%$ \\
\hline Q1 & 6 & 8.7 & 4 & 5.8 & 13 & 18.8 \\
Q2 & 6 & 8.7 & 9 & 13.0 & 8 & 11.2 \\
Q3 & 3 & 4.3 & 7 & 10.1 & 13 & 18.8 \\
Total $=69$ & 18 & 21.7 & 20 & 28.9 & 34 & 48.8 \\
\hline
\end{tabular}

TABLE 7 Summary of MCE results (\%): both groups.

Good MCE Either possible but not good or bad MCE

$\begin{array}{lll}\text { Under 5o group } & 26.9 & 73.1 \\ 5 \text { 0 + group } & 21.7 & 77.7\end{array}$

respondents totalled 101, as there was a greater number of Under 50 respondents. However, the $50+$ group had the same number of respondents as the Singaporean group, as shown in Tables $5^{-7}$ :

Clearly, the rejection rate was much higher across both age groups in the MCE data than in the Singaporean data. The relative frequencies may be calculated as follows:

For the Under 5 os group (78): $65 \mathrm{Bad}, 106$ Possible but not good $=171$ rejections in total, across 468 possible rejections. $171 / 468=36.5 \%$ of the entire group. 


\section{Under 50 Group (MCE)}

\section{Acceptances \\ Rejections}

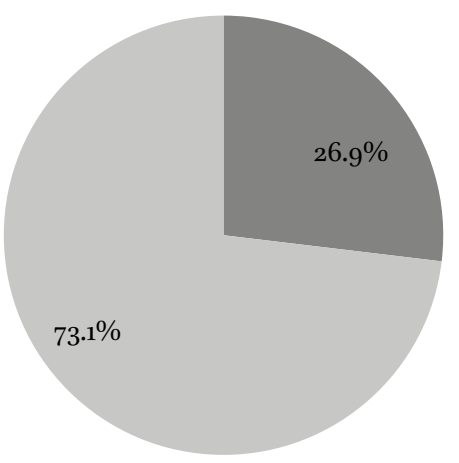

$5^{0+}$ Group (MCE)

Acceptances $\square$ Rejections

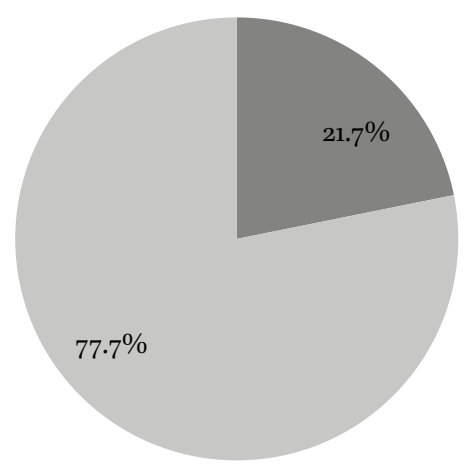

\section{FIGURE 3}

Results summary for the respondents in the Malaysian group aged under $5^{0 .}$

\section{FIGURE 4}

Results summary for the respondents in the Malaysian group aged $5^{0+}$.

For the 50+ group (23), 34 Bad, 20 Possible but not good, across 138 possible rejections. $54 / 138=39.1 \%$ of the entire group $=2.6 \%$ more than the Under 50 . The age grading for the Malaysian respondents was thus not shown to be as significant as in the Singaporean group, and the rejection rate was almost the same for both older and younger respondents.

\section{5}

\section{Discussion}

It is argued, as mentioned earlier, that the differences between the Singaporean groups and the Malaysian groups is simply due to the fact that the Singa- 
poreans tend to have a more frequent usage of English in the community than do the Malaysians, and thus allowing for faster rates of evolution and change. The more conservative profile of the older Singaporean speakers in the survey is therefore believed to be comparable to the more conservative choices of the Malaysian groups in general, and the higher rates of rejection in the distribution of the aspectual marker reflect a less frequent usage of the dialect in the local domain which would otherwise allow for certain semantic features to be 'bleached out' over time. If the surveys do provide an approximate measure of actual usage, the older age-groups in both surveys testify to the correlations between distributional generalization of the aspect marker and the length of time the feature has been in use in the community.

Such examples might appear as testimony to the hypothesis that language change takes place in L1 acquisition, as many (generative) studies have long maintained. However, this hypothesis rules out intra-generational variation, and the variable frequencies of use of already seen in the above age-graded data would need to be explained. There would also be no evidence for the instability of the individual vernacular at various stages of his or her life, as discussed above. The extension of use of a form across generations is merely evidence that younger speakers tend to innovate from an older usage, expanding its distribution to an ever-widening range of functions. As a result, the longer a form is used in a community, the more likely it is to undergo semantic erosion. The data presented are a clear indication that such innovation is or has already taken place in the case of the distribution of already, which is obviously more restricted in its usage with older speakers of Singlish: the perfective aspect marker is dispreferred in contexts in which the event marked by it referred to something accidental or unexpected. This is clearly conveyed in one comment, elicited from a participant aged $40-50$, as part of the Singaporean pilot study: Already is not used for accidents. It's to indicate that something has been done, completed, finished. E.g. Aiya, I send already lah. Note we tend to pronounce it as awready..$^{13}$ There were many comments following the surveys, but some of them did not specify the reason for rejection or acceptance of the sentences, or reveal that they were aware of the precise semantic constraints on the distribution of already. As a preliminary observation, though, the results of the present study do testify to the presence of retention or persistence (Hopper, 1991) in the grammaticalisation of a lexical source item across contact: the context of an accidental event is inconsistent with the lexical meaning of the source item as a predicate adjective meaning 'in a state of preparedness', and indicates that not all of the full range of perfective uses

13 The Singlish discourse particle aiya is used to express dismay, lah is another discourse particle, used for emphasis. 
(completion, inchoativity, and incipience) may yet have been included in its distributional range as one would expect. In previous contact studies of grammaticalisation, there has been little evidence of persistence recorded, to our present knowledge. ${ }^{14}$ Such evidence strongly reinforces the hypothesis of ordinary contact-induced grammaticalisation as an explanation for the presence of already as an aspectual marker in Singapore English, as hypothesized by Matthews and Yip (2009) and Szeto et al (2017).

Although it could be argued that the respondents had perceived other features in the sample sentences which were motivating their responses, many of the responses exploited the "Comments" space on the survey to express their discontent with the use of already, for example (in the Singaporean survey):

(21) a. Why the already?

b. "Lah" is often used in place of already.

c. To make the statements more singlish, instead of using already, can use "liao". It has the same meaning.

And in the Malaysian survey:

d. Already strange because external to the person.

e. Don't need already.

f. Like the already before the verb.

g. Shorter better. Without already ok.

h. We usually use it for sentences like "I have done that already, or "We eat already".

i. Those who speak Hokkien would end their sentences with "liao" instead of already.

j. Good but not gramamtical [sic.]

Interestingly, the suggestions for the use of borrowed aspectual markers such as lah or liao in (21c and 21i) may indicate that the lexical persistence in already is not present in the use of lah or liao, being grammaticalised from lexical source verbs meaning 'finish'. In fact, the translation equivalents of the sample sentences in the substrate languages do permit the co-occurrence of the aspect marker to mark accidental events (see (23) and (24) below), whereas this environment does not admit the distribution of already in Singlish and MCE for many speakers. However, the question is how speakers of Singlish and MCE may have access to the earlier meanings of the lexical source for the aspectual

14 One exception is Bao and Wee's (1999) study on give in Singapore English, cited in Matthews and Yip (2009) as showing persistence of lexifier meaning in contact. However, Bao (2015) finds little evidence for the use of the give-passive in present-day Singapore English. 
marker, in order to understand its distributional limits in present-day usage. Studies described above (section 3.1), using Singapore and Indian English (Ziegeler, 2017), have shown a close similarity between early stages in the pathways of grammaticalisation of the lexifier language and high frequency linguistic environments in the grammaticalisation of an item in the present-day contact situation, as discussed above. Such findings have been hypothesized to indicate a partial recapitulation of the lexifier stages of grammaticalisation. However, already has never been used in standard English to grammaticalise perfective aspect, and so the evidence observed in the data above is not readily explained by replication as recapitulation of the historical functions of the lexifier.

In the case of already, the substrate languages provide the functional model, but the item selected for the substrate model language functions appears to be affected (to a certain extent) by the continued adherence of lexical nuances associated with its historically earlier source form, a quantifier + predicate adjective, all + ready (as seen in 3.3). Thus, two paths of development are observed in the history of already:

(i) a reanalysis + univerbation from quantifier + predicate adjective $\rightarrow$ adverb (standard English); and

(ii) grammaticalisation from adverb $\rightarrow$ aspect marker (Singlish and MCE)

Only the second stage (ii) is an instance of grammaticalisation, and in the present case, an ordinary, contact-induced grammaticalisation. This does not replicate any grammaticalisation in the lexifier, since English has no use for already as a perfective aspect marker, nor is it an example of replica grammaticalisation of the stages of development represented in the model languages, since the persistence shown is from the lexifier. This may be seen below in the translations of the survey examples in the model languages.

\subsection{Substrate Constraints on Distribution}

That the lexical nuances persisting in the case of already cannot be associated with the substrate model languages is shown in present-day Cantonese and Mandarin, the most important substrate and adstrate languages for Singlish and MCE, which do not have the same restrictions, for example: ${ }^{15}$

15 Although there were a number of southern Chinese dialects/languages contributing to the Singaporean substrate, it is usually agreed that they share principal grammatical features (e.g. Bao, 2015: 51). Abbreviations in $(20-22)$ are the following: Poss: possessive 
(Kuala Lumpur) Cantonese:

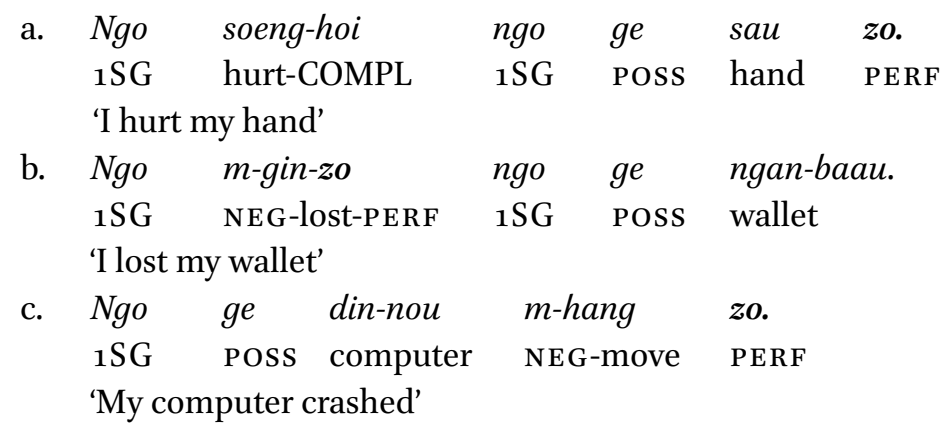

Szeto et al (2017) note that the functional need replicated in the grammaticalisation of already in Hong Kong bilingual children's learner English is found in a combination of two markers, verb-final $z o 2$ and sentence-final laa 3 (and not simply zo2 alone), which together supply the meanings of completion (in zo2) and change-of-state (in laa3) (2017: 496). ${ }^{16}$ However, regardless of how many functional elements provide the actual correspondence, Szeto et al (2017) still find that the nuances of expectation or preparedness are not obligatorily associated with the meaning of the Cantonese model functions, unlike in the standard English use of already.

Mandarin similarly allows perfective markers to co-occur with predicates referring to accidental events: ${ }^{17}$

marker, NEG: negative marker, PERF: perfective, COMPL: complementiser, 1SG: first person singular. Glosses are the authors' own.

16 Zo may occur sentence-finally in Kuala Lumpur Cantonese, possibly due to the influence of contact languages such as Hokkien. Hoi (a habitual marker in Hong Kong English) is used in (20a) with a completive or perfective function similar to liao and $z o$, possibly under the contact influence of Hakka, in which it has this function.

17 However, it is unlikely that in their earlier diachronic functions such forms would have appeared in contexts referring to accidental events (according to Alain Peyraube, p.c.). The lexical sources for marking perfectivity in Chinese were originally derived from a paradigm of verbs with meanings of 'finish' or 'achieve', of which only one was eventually selected, liao/le (了), a process of "lexical unification" according to Peyraube (2009) - or specialization in Hopper (1991). The Cantonese marker $z o$ is believed to have come from the perfective aspect marker in Medieval Chinese (and some present-day dialects) 着 (zhe/zhao/zhuo) (Alain Peyraube and Liu Danqing (p.c.)). 
Mandarin:

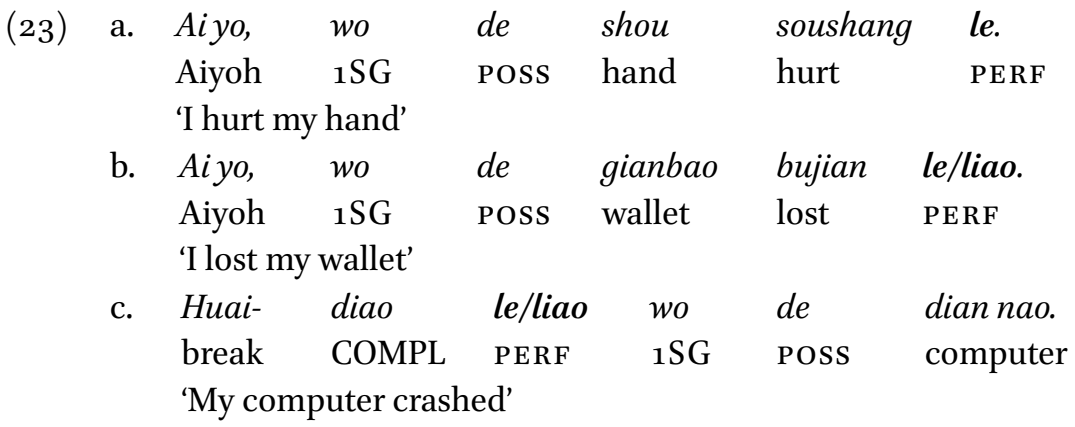

Malay seems to prefer the perfective before the verb. The perfective adverb is sudah (sometimes shortened to dah) in more informal contexts and telah in more formal contexts. ${ }^{18}$

\begin{tabular}{|c|c|c|c|c|}
\hline a. & $\begin{array}{l}\text { Tangan } \\
\text { hand }\end{array}$ & $\begin{array}{l}a k u \\
1 S G\end{array}$ & $\begin{array}{l}(s u) d a h \\
\text { PERF }\end{array}$ & $\begin{array}{l}\text { sakit. } \\
\text { hurt }\end{array}$ \\
\hline & \multicolumn{4}{|c|}{ 'I hurt my hand' } \\
\hline \multirow[t]{2}{*}{ b. } & $\begin{array}{l}\text { Dompet } \\
\text { wallet }\end{array}$ & $\begin{array}{l}\text { saya } \\
1 \mathrm{SG}\end{array}$ & $\begin{array}{l}(s u) d a h \\
\text { PERF }\end{array}$ & $\begin{array}{l}\text { hilang. } \\
\text { lose }\end{array}$ \\
\hline & \multicolumn{4}{|c|}{ 'I lost my wallet' } \\
\hline c. & $\begin{array}{l}\text { Komputer } \\
\text { computer }\end{array}$ & $\begin{array}{c}\text { saya } \\
{ }_{1} \mathrm{SG}\end{array}$ & $\begin{array}{l}\text { (su)dah } \\
\text { PERF }\end{array}$ & $\begin{array}{l}\text { rosak. } \\
\text { break }\end{array}$ \\
\hline
\end{tabular}

(Su)dah can also occur at the end of the utterance by itself or together with its pre-verbal use (the latter strategy is for emphasis), as in Colloquial Malay:

(25) $\begin{aligned} & \text { Kau } \\ & \text { OK }\end{aligned}$ tak
2SG OK NEG
('Are you OK or not'?)
Darah dah stop dah. Tangan rasa kebas sikit.
blood PERF 1 SG PERF hand feel numb little
'The blood has stopped already. Hand feels a little numb'

Zaini, Adib. 2011. Zombijaya. Petaling Jaya: Buku Fixi, p. 5.

18 The Malay native speaker consulted said the already in the English sentences should be omitted or replaced with lah. She also said that sudah was optional. 
Once again, then, the rejection of already with accidental events seems to be unrelated to the use of its functional model in the substrate (and adstrate) languages. Olssen (2013), moreover, finds that Singapore Malay does not allow su$d a h$ with an example similar to (24b), the shorter form $d a h$ being possible, and also shows that sentence-final le may occur in Mandarin translations of the same example. The acceptability of $d a h$, according to Olssen (2013), is an indication that it is no longer a iamitive but is now a perfective aspect marker (the shorter form being also a clear indication of phonological erosion familiar to later stages of grammaticalisation). Thus, although Bao's (2005; 2015) claims are for a complete transfer of the perfective aspectual system of Chinese, it would appear that the model language functions have proceeded further in their grammaticalisation than those of the replica languages.

The question remaining, though, is how speakers may access the constraints on the adverb's distribution in this way if the constraints are not reflected in the substrate model languages. In earlier studies (as mentioned above, e.g. Matras and Sakel (2007: 833-4) it was noted that speakers in contact may have access to polysemies in the form of an item grammaticalising in contact, which justify their selection of that form to replicate the model function required. Such constraints may also be explained by the continuing presence of the lexical source construction in the replica language itself:

(26) The stupid shipment is three weeks ago now they send. You think by the time the fellow will still be on the ball you know what I mean you know this type usually when the starting uh whoa everybody all ready to go off fired up you know. Three weeks down the road alamak these guys all forgotten already man. So then wa bo chap ... you know uuh don't care don't care you know. Then you know when you don't care huh. The law of uh what's that Thermodynamics ...19

(ICE-Singapore: S1A-og6\#X349:2:E)

This was one of two examples found in the spoken section of the ICESIN(GAPORE) Corpus (no examples were found in the written section, and only one was found in the ICE-GB (21)). It is also interesting that both the source form, all ready, and the perfective marker, already, are used in the same

19 Alamak is a borrowed discourse marker from Malay, expressing dismay. Wa bo chap is a phrase in Hokkien meaning 'I couldn't care less.' Liao in (24b) is also used in Hokkien for 'already', 'finish'. Lo (in (28) is a discourse marker from Cantonese with a meaning of obviousness. 
utterance by the same speaker. ${ }^{20} \mathrm{~A}$ number of examples could also be found in Malaysian English online forums:

(27) hmmm..he say hq no stock. scold him also no use lo. [...] accessories all ready liao but car not yet ready

https://forum.lowyat.net/topic/4222823/+1400

In (27), moreover, there is a non-redundant co-occurrence of all + ready with the Hokkien aspect marker model, liao replacing already (the speaker may have wished to avoid using already alongside its source construction). Thus, the continued use of the predicate adjective source of already as shown in both examples illustrates that the 'split' in the history of the adverb in monolingual situations is transferred across contact, in which both the lexical source of the adverb, and the adverb itself, are replicated in the contact variety (a double split).

This does not mean that already emerged out of all + ready in the brief history of Singlish and MCE; naturally, both items must have present in the dialect at the time of contact (in the $19^{\text {th }}$ century). However, the continued cooccurrence of the source concept from which the adverbial function evolved, appearing alongside the grammaticalised function of an aspect marker, has obviously had an influence on the distribution of the grammatical marker for some speakers. In the contact situation, then, the presence of such splits enables the speaker to identify meanings which are not otherwise accessible diachronically and may place constraints on distribution at later stages. In many

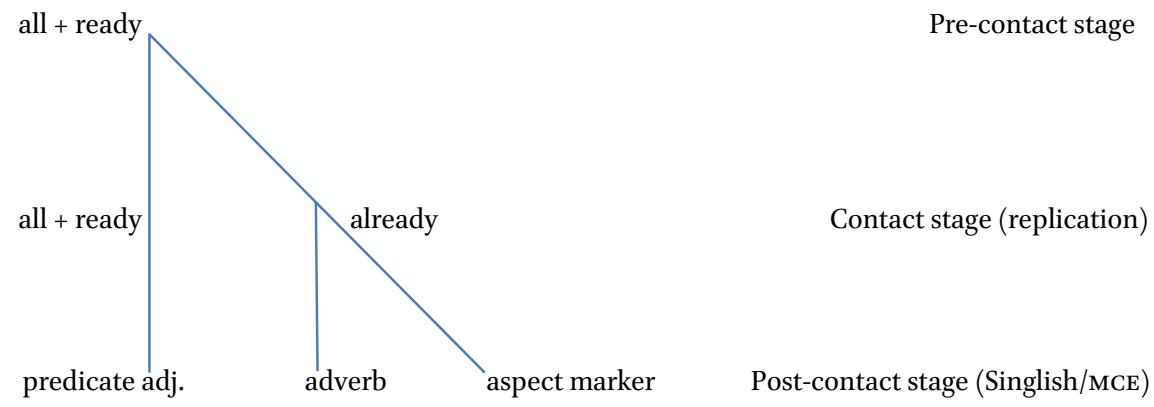

FIGURE 5 Transfer of all ready/already as a split (divergence) across contact, and subsequent grammaticalisation as an aspect marker in Singlish and MCE.

20 The likelihood of the use of already in (27) being a standard use is not ruled out, but there is also the possibility that it would be placed pre-verbally and not in clause-final position, if that were the case. 
TABLE 8 Replication of functional attributes of already in the Singaporean and Malaysian contact situation.

\begin{tabular}{lll}
\hline Singlish/MCE & English & Chinese languages $(+$ \\
already & already & Malay):le/liao/zo/(su)dah
\end{tabular}

\begin{tabular}{lll}
\hline (i) adverb - 'in a state of & adverb - 'in a state of & perfective aspect: \\
preparedness'; 'completion & preparedness'; 'completion & -completion \\
prior to expectation' & prior to expectation' & -inchoativity \\
(ii) perfective aspect: & & -incipience \\
-completion & & -anterior \\
-inchoativity & \\
-incipience & & \\
-anterior &
\end{tabular}

cases of grammaticalisation in contact, the selection of the lexical source to be replicated in this way is therefore no mystery and does not entail that contact speakers understand the diachrony of their language - the diachrony may still be present at the time of contact (this tendency is also noted in Matthews and Yip (2009). Thus, this is a case of ordinary contact-induced grammaticalisation which has been mediated by the lexifier. The functional features which are replicated are shown in the table below, following the model of Lefebvre (2011: 22-23):

Matthews and Yip's (2009) study does not indicate any likelihood of the grammaticalisation of already being represented in gradual stages; all the functions of the model language are replicated at roughly the same time in their study. However, as the present study as shown, the presence of persistence in older generation Singaporean speakers along with the evidence from all speakers of MCE suggests that an earlier stage may be hypothesized in which the completive function of the aspectual range may be more restricted in its distributional grammaticalisation. Thus, based on the data obtained, the following (hypothetical) stages may be proposed for the (post-contact) grammaticalisation of already:

Stage o: adverb

Stage 1: (i) adverb;

(ii) perfective marker, restricted in its completive function to nonaccidental events 
Stage 2: (i) adverb;

(ii) perfective marker, unrestricted in all model language functions.

Such observations may then challenge the hypothesis of Total Systemic Transfer in Singapore English (Bao, 2005; 2015), and its claims that already is not a case of grammaticalisation, but of substratum transfer (Bao, 2015: 297-8). What is transferred is the substratum function; the lexical expression of that function, using material from the lexifier, is affected to some extent by the semantic constraints on the historical source of that material. In Bao's (2005, 2015) theory of transfer of an entire aspectual system from the substrate, the lexifier function is viewed in terms of its regulatory constraints on the morphosyntax of the replicating language, and in this regard, Bao deals mainly with the issue of the transfer of constituent order.

However, the question which arises now is, if the Lexifier Filter regulates the System Transfer, what regulates the Lexifier Filter? In the present study, the abstract definition of a Lexifier Filter may be advanced to a further stage, as indicated by the data above: it is not only the morphosyntax which places constraints on the distribution of transferred items, but also the semantics, suggesting that the Lexifier Filter is a much more powerful influence on the transfer of features in contact than originally perceived. The presence of lexical retention in the transfer process can be readily observed in a case of ordinary contact-induced grammaticalisation, as shown above. However, the extent to which the aspect marker has grammaticalised in the replica languages is not the same as in the model languages, and it still retains, for some speakers, traces of its original lexical source meaning from the pre-contact replica language or lexifier. We are reminded that the same constraints exhibited in the distribution of already are not found in the present-day aspectual model functions in Mandarin Chinese or Cantonese, and Mandarin le and Cantonese zo may be used with any completed event, accidental or otherwise. Olssen (2013) also finds no similar constraints on the use of the aspect marker dah in Malay. It seems evident that the distributional constraints (also a puzzle for Soh (2009) can only be attributed to the continued presence of the lexical source of the aspect marker in the replica language itself.

The present study has provided a rapid, spontaneous survey of attitudes and intuitions towards the use of already as an aspect marker in Singlish, and 
reveals clear distributional limitations relating to the development of the adverb from a predicate adjective. As such it stands as an empirical testimony to the principle of persistence (Hopper, 1991) and an indication that the gradual generalization of linguistic environments typical of grammaticalisation may also appear in contact situations. Hopper and Traugott (2003: 96) mention the fact that constraints on a grammaticalising item may often only be understood in the light of diachronically earlier meanings, and describe this as one of the most damaging pieces of evidence against sudden emptying of meaning or bleaching. In the present study, it is understood as evidence for the contactinduced grammaticalisation of already, together with the age-grading and generational differences reflected in both surveys - indicating that ordinary contact-induced grammaticalisation may be attributed a degree of gradualness after all.

Distributional constraints in grammaticalisation can be measured by individual intuitions, though this is not a fail-proof indication of the usage of the feature, and should not be understood as definitive of its grammaticalisation level with any particular group: many speakers will willingly accept an item in isolation even though they may never use the item in the relevant contexts themselves. On the contrary, there may be differences between those who mark an item as unacceptable and yet may occasionally use it themselves. For this reason, the survey should not be taken as a watertight representation of actual usage within the community of speakers, and a more detailed, longitudinal survey involving closer observation of the speakers concerned would be necessary to reinforce the claims made on the basis of the present data. Nevertheless, the trends are interesting, in view of the greater number of intuitive rejections of the examples of already occurring in expressions describing accidental events from the older age-groups and from a less grammaticalised contact dialect, MCE. Such data should be taken as an indication of a more conservative use, reflecting the stronger adherence of lexical source meanings in the grammaticalisation of the aspect marker in MCE than in Singlish, and in the older age-groups, for both dialects. The differences between the older and the younger Singaporean groups also reveal the likelihood that a more rapid level of grammaticalisation of already may be found with younger speakers. The prospect of different rates of grammaticalisation in contact has not been the topic of a great deal of discussion in the literature so far, and is worthy of further research.

At the same time, for the promotion of other theories of contact, it provides a welcome conciliation. Theories of contact involving reference to a Lexifier 'Filter', such as Bao $(2005 ; 2015)$ has described, may be discussed alongside contact grammaticalisation theories and within the framework of Matthews and 
Yip (2009) and Szeto et al 's (2017) case of already as ordinary contact-induced grammaticalisation. In the present case of already in Singlish, there is ample evidence in the observations of persistence that grammaticalisation was involved in replicating the perfective aspectual system of the substrate model languages. The role of the Lexifier Filter alluded to in Bao's studies may thus be expanded to refer to not only the morphosyntax of the lexifier, but the lexicon also, since grammaticalisation entails no clear separation across such categories. It remains, then, for future studies to exploit the phenomenon of lexical retention in contact grammaticalisation in greater depth and in broader scope.

\section{References}

Alsagoff, Lubna. 2010. English in Singapore: culture, capital and identity in linguistic variation. World Englishes 29: 336-348.

Alsagoff, Lubna \& Chee Lick Ho. 1998. The grammar of Singapore English. In Joseph A. Foley, Thiru Kandiah, Bao Zhi-Ming, Anthea Fraser Gupta, Lubna Algasoff, Ho Chee Lick, Lionel Wee, Ismail S. Talib \& Wendy Bokhorst-Heng, English in New Cultural Contexts. Reflections from Singapore, 127-151. Singapore: Oxford University Press [Singapore Institute of Management].

Ansaldo, Umberto. 2009. Contact Languages. Ecology and Evolution in Asia. Cambridge: Cambridge University Press.

Asmah Haji, Omar. 2012. Pragmatics of maintaining English in Malaysia's education system. In Ee Ling Low and Azirah Hashim (eds.), English in Southeast Asia: Features, Policy and Language in Use, 155-175. Amsterdam/Philadelphia: John Benjamin.

Azirah Hashim. 2002. Culture and identity in the English discourses of Malaysians. In A. Kirkpatrick (ed.), Englishes in Asia: Communication, Identity, Power and Education, 75-94. Melbourne: Language Australia.

Bailey, Guy. 2004. Real and apparent time. In JK Chambers, Peter Trudgill, and Natalie Schilling Estes (eds.), The Handbook of Language Variation and Change, 312-332. Oxford: Blackwell.

Bao, Zhiming. 1995. Already in Singapore English. World Englishes 14: 181-188.

Bao, Zhiming. 2001. The origin of empty categories in Singapore English. Journal of Pidgin and Creole Languages 16: 275-319.

Bao, Zhiming. 2005. The aspectual system of Singapore English and the systemic substratist explanation. Journal of Linguistics 41: 237-267.

Bao, Zhiming. 2009. One in Singapore English. Studies in Language 33: 338-365.

Bao, Zhiming. 2010. A usage-based approach to substratum transfer: the case of four unproductive features in Singapore English. Language 86: 792-820. 
Bao, Zhiming, 2015. The Making of Vernacular Singapore English: System, Transfer and Filter. Cambridge: Cambridge University Press.

Bao, Zhiming and Huaqing Hong. 2006. Diglossia and register variation in Singapore English. World Englishes 25: 105-114.

Baskaran, L. 2004. Malaysian English: morphology and syntax. In Bernd Kortmann, Kate Burridge, Rajend Mesthrie, Edgar W. Schneider and Clive Upton (eds.), A Handbook of Varieties of English. Vol. 1, 1034-1046. Berline: Mouton de Gruyter.

Brinton, Laurel J., and Elizabeth Closs Traugott. 2005. Lexicalization and Language Change [Research Surveys in Linguistics 4]. Cambridge: Cambridge University Press.

Bruyn, Adrienne. 2009. Grammaticalization in creoles: Ordinary and not-so-ordinary cases. Studies in Language 3: 312-337.

Butcher, John G. 1979. The British in Malaya, 1880-1941: The Social History of a European Community in Colonial South-east Asia. Oxford: Oxford University Press.

Bybee, Joan, and William Pagliuca. 1987. The evolution of future meaning. In A.G. Ramat, O. Carruba, and G. Bernini (eds.), Papers from the Seventh International Conference on Historical Linguistics, 109-122. Amsterdam/Philadelphia: John Benjamins.

Bybee, Joan, Revere D. Perkins \& William Pagliuca. 1994. The Evolution of Grammar: Tense, Aspect and Modality in the Languages of the World. Chicago: University of Chicago Press.

Chen, Jason Yingjie. ms. Already in Singapore Colloquial English. Undergraduate academic exercise (2008). National University of Singapore.

Cukor-Avila, Patricia. 200o. The stability of individual vernaculars. University of North Texas MS. Dahl, Östen. 2006. Relativism and universalism from the perspective of areal typology an grammaticalization theory. Plenary talk presented at the 39th Annual Meeting of the Societas Linguistica Europaea, University of Bremen, 30 August-2 September.

Deuber, Dagmar. 2010. Modal verb usage at the interface of English and a related creole: A corpus-based study of can/could and will/would in Trinidadian English.Journal of English Linguistics 38.105-142. DOI: 10.1177/0075424209348151.

Fong, Vivienne. 2017. World Englishes and syntactic and semantic theory. In Markku Filppula, Juhani Klemola, and Devyani Sharma (eds.), The Oxford Handbook of World Englishes, 84-102. New York: Oxford University Press.

Gast, Volker and Johan van der Auwera. 2012. What is 'contact-induced grammaticalization'? Evidence from Mayan and Mixe-Zoquean languages. In Björn Wiemer, Bernard Wälchli and Björn Hansen (eds.), Grammatical Replication and Borrowability in Language Contact, 381-426. Berlin: De Gruyter Mouton.

Gupta, Anthea Fraser. 1994. The Step-Tongue. Children's English in Singapore. Clevedon: Multilingual Matters. 
Haspelmath, Martin, Matthew S. Dryer, David Gil and Bernard Comrie (eds.). 2005. World Atlas of Language Structures. Oxford: Oxford University Press.

Haspelmath, Martin, Matthew S. Dryer, David Gil, and Bernard Comrie (eds.). 2008. The World Atlas of Language Structures Online. Oxford: Oxford University Press. München: Max Planck Digital Library. http://wals.info/.

Heine, Bernd and Tania Kuteva. 2003. On contact-induced grammaticalization. Studies in Language 27: 529-572.

Heine, Bernd and Tania Kuteva. 2005. Language Contact and Grammatical Change. Cambridge: Cambridge University Press.

Heine, Bernd, and Mechthild Reh. 1984. Grammaticalization and Reanalysis in African Languages. Hamburg: Helmut Buske.

Ho, Mian Lian and John Platt. 1993. Dynamics of a Contact Continuum. Singaporean English. Oxford: Clarendon.

Hopper, Paul J. 1987. Emergent grammar. Proceedings of the 13th Annual Meeting of the Berkeley Linguistics Society: 139-57.

Hopper, Paul J. 1991. On some principles of grammaticization. In Elizabeth C. Traugott and Bernd Heine (eds.), Approaches to Grammaticalization, Vol. 1, 17-35. Amsterdam: John Benjamins.

Hopper, Paul J. and Elizabeth Closs Traugott. 2003. Grammaticalization. Cambridge: Cambridge University Press.

Kuteva, Tania, Seongha Rhee, Debra Ziegeler, and Jessica Sabban (to appear). Are you the Queen of England, or what? On sentence-final what. Forthcoming in Journal of Language Contact.

Kwan-Terry, Anna. 1989. The specification of stage by a child learning English and Cantonese simultaneously: a study of acquisition processes. In Dechert, H. W. and Raupach, M. (eds.), Interlingual Processes, 33-48. Tübingen: Gunter Narr Verlag.

Labov, William. 1966 [2006]. The Social Stratification of English in New York City. Cambridge, UK: Cambridge University Press.

Lee, Sarah. 2015. An Interactional Account of Multilingual Usage Patterns in Kuala Lumpur, Malaysia - a High Contact Area. Ph.D dissertation, Rice University.

Lefebvre, Claire. 1998. Creole Genesis and the Acquisition of Grammar: The case of Haitian Creole. Cambridge: Cambridge University Press.

Lefebvre, Claire. 2011. The contribution of relexification, grammaticalization, and reanalysis to creole genesis and development. In Clancy Clements, J, and Shelome Gooden (eds.), Language Change in Contact Languages, 19-52. Amsterdam: John Benjamins.

Leimgruber, Jacob R. E. 2009. Modelling variation in Singapore English. PhD dissertation, University of Oxford.

Li, Charles N., and Sandra A. Thompson. 1989[1991]. Mandarin Chinese: A Functional Reference Grammar. Berkeley: University of California Press. 
Lim, Lisa. 2007. Mergers and acquisitions: on the ages and origins of Singapore English particles. World Englishes 26: 446-473.

Matras, Yaron and Jeanette Sakel. 2007. Investigating the mechanisms of pattern replication in language convergence. Studies in Language 31: 829-865.

Matthews, Stephen and Virginia Yip. 20o9. Contact-induced grammaticalization: Evidence from bilingual acquisition. Studies in Language 33: 366-395.

Mühlhaüsler, Peter. 1986. Bonnet blanc and blanc bonnet: adjective-noun order, substratum and language universals. In Pieter Muysken and Norval Smith (eds.), Substrata versus Universals in Creole Genesis, 41-56. Amsterdam/Philadelphia:John Benjamins.

Mufwene, Salikoko S. 1990. Transfer and the substrate hypothesis in creolistics. Studies in Second Language Acquisition 12: 1-23.

Mufwene, Salikoko. 2008. Language Evolution, Contact, Competition and Change. London: Continuum.

Mustanoja, Tauno F. 1960. A Middle English Syntax. Helsinki: Société Néophilologique.

Newbrook, Mark. 1997. Malaysian English: Status, norms, some grammatical and lexical features. In Edgar W. Schneider (ed), Englishes Around the World, Vol. 2: Carribean, Africa, Asia, Australasia, 229-256. Amsterdam:John Benjamins.

OED Online = Oxford English Dictionary Online, 3rd edition (updated 2012). http:// www.oed.com.ezproxy.univ-paris.fr.

Olssen, Bruno. 2013. Iamitives. Perfects in Southeast Asia and beyond. Masters thesis, University of Stockholm.

Peyraube, Alain. 2009. Hanyu de ti he shi (Tense and Aspect in Chinese). In Li Feng, Yang Yonglong and Changcai Zhao (eds.) Hanyu shiti de lishi yanjiu (Historical Research on Chinese Tense and Aspect), 1-9. Peking: Yuwen chubanshe (Language editions).

Pillai, Stephanie. 2012. Colloquial Malaysian English. In Bernd Kortmann and Kerstin Lunkenheimer (eds.), The Mouton World Atlas of Variation in English, 573-584. Berlin/Boston: Mouton de Gruyter.

Platt, John and Heidi Weber. 1980. English in Singapore and Malaysia.Kuala Lumpur: Oxford University Press.

Platt, John T., Heidi Weber and Mian Lian Ho. 1984. The New Englishes. London: Routledge \& Kegan Paul.

Pennycook, Alistair. 1994. The Cultural Politics of English as an International Language. London: Longman.

Ridge, Brian. 2004. Bangsa Malaysia and Recent Malaysian English Language Policies. Current Issues in Language Planning 5: 407-423.

Romaine, Suzanne, and Deborah Lange. 1991. The case of like as a marker of reported speech and thought: a case of grammaticalization in progress. American Speech 66: 227-279. 
Sandhu, K.S. 1993. The Coming of Indians to Malaya. In Sandhu Singh, K.S. and A. Mani (eds.), Indian Communities in Southeast Asia, 151-189. Singapore: Times Academic Press.

Sankoff, David and Suzanne Laberge 1978. The linguistic market and the statistical explanation of variability. In David Sankoff (ed.), Linguistic Variation: Models and Methods, 239-250. New York: Academic Press.

Schneider, Edgar W. 2003. The dynamics of New Englishes: From identity construction to dialect birth. Language 79: 233-281.

Schwenter, Scott A. 1994. The grammaticalization of an anterior in progress: evidence from a Peninsular Spanish dialect. Studies in Language 18: 71-111.

Siemund, Peter. 2013. Varieties of English: A Typological Approach. Cambridge: Cambridge University Press.

Siemund, Peter, and Lijun Li. 2017. Towards a diachronic reconstruction of Colloquial Singapore English. In D. Ziegeler and Zhiming Bao (eds.), Negation and Contact. With Special Focus on Singapore English, 11-32. Amsterdam: Benjamins.

Smith, Carlota S. 1991. The Parameter of Aspect. Dordrecht: Kluwer.

Szeto, Pui Yiu, Stephen Matthews, and Virginia Yip. 2017. Multiple correspondence and typological convergence in contact-induced grammaticalization. Journal of Language Contact 10: $485^{-518 .}$

Tagliamonte, Sali, Mercedes Durham, and Jennifer Smith. 2014. Grammaticalization at an early stage: future be going to in conservative British dialects. English Language and Linguistics 18: $75^{-108 .}$

Tan, Chee Beng. 200o. Socio-Cultural Diversities and Identities. In Lee Kam Hing and Tan Chee Beng (eds.) The Chinese in Malaysia, 37-70. Kuala Lumpur, Oxford University Press.

Unesco. 1973. The Educational Statistics System of Malaysia 1972. Bangkok: Unesco Regional Office for Education in Asia. http://unesdoc.unesco.org/images/oooo/ oooogo/oogo59eb.pdf.

Wagner, Suzanne E. 2012. Age grading in sociolinguistic theory. Language and Linguistics Compass 6: 371-382.

Wagner, Suzanne E. \& Gillian Sankoff. 2011. Age grading in the Montreal French inflected future. Language Variation and Change 23: 1-39.

Weinreich, Uriel. 1953. Languages in Contact. The Hague: Mouton.

Ziegeler, Debra P. 2014. Replica grammaticalisation as recapitulation: The other side of contact. Diachronica 31: 106-141.

Ziegeler, Debra P. 2017. Historical replication in contact grammaticalisation. In Daniel van Olmen, Hubert Cuyckens and Lobke Ghesquiere (eds.), Aspects of Grammaticalization: (Inter)subjectification, Analogy and Unidirectionality, 311-352. Berlin: Mouton de Gruyter. 


\section{Corpora Used}

The Helsinki Corpus of English Texts (1991). Department of Modern Languages, University of Helsinki. Compiled by Matti Rissanen (Project leader), Merja Kytö (Project secretary); Leena Kahlas-Tarkka, Matti Kilpiö (Old English); Saara Nevanlinna, Irma Taavitsainen (Middle English); Terttu Nevalainen, Helena Raumolin-Brunberg (Early Modern English). (see the Corpus Resource Database, CoDR Helsinki).

The ICE Corpus = The International Corpus of English: http://ice-corpora.net/ice/avail .htm.

Corpus of Middle English Prose and Verse: available online at: https:/quod.lib.umich .edu/c/cme/lib.umich.edu/c/cme/. 